\title{
AzuCR RNA modulates carbon metabolism as a dual-function RNA in
}

\section{Escherichia coli}

\section{Medha Raina ${ }^{1, \hbar \dagger}$, Jordan J. Aoyama ${ }^{1, \hbar}$, Shantanu Bhatt ${ }^{1, \dagger}$, Brian J. Paul ${ }^{1, \dagger}$, Gisela Storz ${ }^{1, *}$}

${ }^{1}$ Division of Molecular and Cellular Biology, Eunice Kennedy Shriver National Institute of Child Health and Human Development, Bethesda, MD 20892-5430, USA.

*Corresponding author. Tel: +1 402 0968; E-mail: storzg@mail.nih.gov

¥These authors contributed equally to this work

$†$ Present Address: Catalent Pharma Solutions, Baltimore, MD 21201

†Present address: Department of Biology, Saint Joseph’s University, Philadelphia, PA 19131

‡Present address: DuPont Nutrition \& Biosciences, Wilmington, DE 19803

Keywords sRNA, catabolite repression, glycerol dehydrogenase, Hfq, ProQ

Running Title Dual-function regulator of metabolism 


\begin{abstract}
Bacteria have evolved small RNAs (sRNAs) to regulate numerous biological processes and stress responses. While sRNAs generally are considered to be "noncoding”, a few have been found to also encode a small protein. Here we describe one such dual-function RNA that modulates carbon utilization in Escherichia coli. The 164 nucleotide RNA was previously shown to encode a 28 amino acid protein (denoted AzuC). We discovered the membrane-associated AzuC protein interacts with GlpD, the aerobic glycerol-3-phosphate dehydrogenase, leading to increased GlpD activity. Overexpression of the RNA encoding AzuC results in a growth defect in glycerol and galactose medium. The defect in galactose medium was still observed for a stop codon mutant derivative, suggesting a potential regulatory role for the RNA. Consistent with this observation, we found that $c a d A$ and galE are repressed by base pairing with the RNA (denoted AzuCR). Interestingly, translation of AzuC interferes with the observed repression of $c a d A$ and galE by AzuCR and base pairing interferes with AzuC translation, demonstrating that the translation and base pairing functions compete.
\end{abstract}




\section{Introduction}

Bacteria are exposed to rapidly changing environmental conditions including variations in carbon availability, $\mathrm{pH}$, temperature, and osmolarity, to name a few. To survive these fluctuating conditions, bacterial cells have fast, flexible, and energy-efficient mechanisms to regulate protein levels and activity. Changes in nutrient availability or stress detected by the cell are transduced into changes in the activation or repression of transcription, post-transcriptional changes to mRNA stability, modulation of mRNA translation as well as the modification of protein stability or activity.

The cAMP receptor protein (CRP), a sequence-specific DNA binding protein, is a key regulator of transcription in response to changes in carbon source availability in E. coli. When the levels of the preferred carbon source glucose are low, the small molecule cAMP is synthesized. cAMP binds and activates the highly-conserved CRP transcription factor, which in turn activates genes for the uptake and utilization of alternative carbon sources in a process termed carbon catabolite repression (CCR) (reviewed in (Soberón-Chávez et al., 2017)).

Several small RNAs (sRNAs), which modulate the stability or translation of mRNAs through short base pairing interactions and are major post-transcriptional regulators in bacteria (reviewed in (Wagner \& Romby, 2015)), also have been found to impact carbon metabolism in E. coli. These include GlmZ, ChiX, SgrS and the CRP-repressed sRNAs Spot 42 and CyaR (reviewed in (Papenfort \& Vogel, 2014, Durica-Mitic et al., 2018)). The base-pairing sRNAs require RNA chaperones such as Hfq and ProQ for their stability and optimal pairing with their target mRNAs (reviewed in (Holmqvist \& Vogel, 2018, Updegrove et al., 2016, Olejniczak \& Storz, 2017)). 
Base-pairing sRNAs generally are thought not to encode proteins and thus are often referred to as noncoding RNAs. However, a few sRNAs have been shown to be translated to produce small proteins and thus are denoted "dual-function RNAs" (reviewed in (Raina et al., 2018)). Computational analyses of the genomes of fourteen phylogenetically diverse bacteria predicted that a number of other sRNAs contain small open reading frames (sORFs) that could encode proteins between 10-50 amino acids (Friedman et al., 2017). Nevertheless, translation of these sORFs has only been documented in a limited number of cases. Even fewer sRNA-encoded protein products have experimentally been demonstrated to have a function.

Small proteins of less than 50 amino acids generally have been long overlooked due to many challenges related to their annotation and biochemical detection. The few that have now been studied show that small proteins modulate diverse cellular functions ranging from morphogenesis and cell division to transport, enzymatic activities, regulatory networks, and stress responses by forming complexes with larger proteins (reviewed in (Storz et al., 2014, Hemm et al., 2020)).

To date, the only dual-function RNA characterized in E. coli is SgrS (Wadler \& Vanderpool, 2007). The SgrS RNA was first found to protect cells against elevated levels of glucose phosphate by regulating the stability and translation of mRNAs encoding proteins involved in glucose transport and catabolism (Vanderpool \& Gottesman, 2004). The RNA subsequently was shown to encode a 43 amino acid protein, SgrT, which interacts with the glucose importer PtsG to block glucose transport and promote utilization of nonpreferred carbon sources to maintain growth during glucose-phosphate stress (Lloyd et al., 2017, Wadler \& Vanderpool, 2007). Thus both the sRNA and its encoded small protein act together to repress glucose import to relieve glucose phosphate stress. 
The 164 nt RNA initially denoted IS092 or IsrB (now denoted AzuCR) was identified in a bioinformatic search to find sRNA genes in E. coli (Chen et al., 2002), but not characterized as an sRNA. Later, this RNA was shown to encode an 28 amino acid sORF (Hemm et al., 2008) (Fig 1A). Synthesis of the small protein was documented by the detection of a tagged derivative (Hemm et al., 2008) and is supported by data indicating ribosome binding to the RNA (Weaver et al., 2019) (Fig EV1A). While the protein, denoted AzuC, is only conserved in a limited number of enteric bacteria (Fig EV1B), expression of AzuC was found to be highly regulated. The levels of the tagged small protein were elevated for growth in glucose compared to glycerol due to CRP-mediated repression in the absence of glucose (Hemm et al., 2010). AzuC-SPA levels also were shown to be reduced under anaerobic conditions but induced upon exposure to low $\mathrm{pH}$, high temperature, and hydrogen peroxide suggesting an important role in cellular stress responses (Hemm et al., 2010).

Here we show that $\mathrm{AzuC}$ is associated with the membrane and binds GlpD, an enzyme required for glycerol catabolism, increasing GlpD activity. Additionally, we document that the transcript acts as a regulatory sRNA, denoted AzuR, repressing expression of $\operatorname{cad} A$, a lysine decarboxylase involved in maintaining $\mathrm{pH}$ homeostasis, and galE, encoding UDP-glucose 4epimerase, through direct base pairing. Thus, AzuCR has mRNA and sRNA activities in two different pathways. The protein coding and base-pairing sequences overlap, and we find that there is inherent competition between the two activities. Intriguingly, while the transcript base pairs with other mRNAs as a regulator, translation of AzuC itself is repressed by the FnrS sRNA, an sRNA that also represses GlpD synthesis. 


\section{Results}

\section{AzuC protein and mRNA levels are discordant for cells grown in glucose and low pH glycerol}

Previous analysis of chromosomally-encoded AzuC, which was C-terminally tagged with the sequential peptide affinity (SPA) tag, showed that AzuC-SPA protein levels were elevated in cells grown in minimal medium with glucose compared to glycerol as well as in $\mathrm{pH} 5.5$ compared to $\mathrm{pH} 7.5$, and decreased under anerobic conditions (Hemm et al., 2010). The decreased levels in minimal glycerol medium and part of the $\mathrm{pH}$-induction were attributed to CRP-mediated repression of $a z u C$ mRNA transcription.

To further evaluate the conditions under which AzuC-SPA and $a z u C$ mRNAs levels are highest, strains were cultured in M63 media supplemented with glucose or glycerol at pH 7.0 and 5.5, and in M63 galactose at pH 7.0 (the strain was unable to grow in M63 galactose at pH 5.5). Cells were collected in exponential $\left(\mathrm{OD}_{600} \sim 0.5\right)$ and stationary $\left(\mathrm{OD}_{600} \sim 1.5\right)$ phase (Fig 1B). As observed previously, AzuC-SPA levels were significantly higher in glucose compared to glycerol and galactose. A notable exception was the elevated AzuC-SPA levels in cells grown to stationary phase in glycerol at $\mathrm{pH}$ 5.5. As expected for a CRP-regulated transcript, $a z u C$ mRNA levels were low for all conditions except for cells growing exponentially in glucose. The discordance between AzuC-SPA protein levels and $a z u C$ mRNA levels in glycerol at pH 5.5 raised the possibility that translation and/or RNA or protein stability is regulated and that the protein and RNA may have different roles.

$\mathrm{Hfq}$ is a key regulator of posttranscriptional regulation in many bacterial cells (reviewed in (Holmqvist \& Vogel, 2018, Updegrove et al., 2016)). To determine whether Hfq had any impact on AzuC, AzuC-SPA levels were compared in wild type and $\Delta h f q$ cells grown to 
stationary phase under the same conditions as above (Fig 1C). AzuC-SPA levels were elevated in the $\Delta h f q$ strain for the cells grown in M63 galactose. This observation is consistent with potential posttranscriptional repression by Hfq and base-pairing sRNAs. However, before delving further into the regulation of $\mathrm{AzuC}$ expression, we wanted to learn more about the function of this 28 amino acid protein.

\section{AzuC protein is localized to the membrane}

Information about the subcellular localization of proteins can give clues about possible interacting partners and functions in the cell. Secondary structural predictions suggested that AzuC has the potential to fold into an amphipathic helix (Fig 2A), indicating the protein might associate with the membrane. To test this, AzuC-SPA cells grown in M63 glucose to $\mathrm{OD}_{600} \sim 1.0$ were lysed, and cell extracts were homogenized and fractionated into soluble, inner membrane and outer membrane fractions by sucrose cushion fractionation (Fontaine et al., 2011, Rhoads et al., 1984). Consistent with the secondary structure prediction, immunoblot analysis of the fractions showed that AzuC-SPA was enriched in the inner membrane fraction, while the OmpA control protein was enriched in the outer membrane fraction (Fig 2B). Similar fractionation of untagged AzuC, expressed from a plasmid and detected by $\alpha$-AzuC antiserum, also showed enrichment in the membrane fraction (Fig EV2A).

The localization of AzuC to the membrane was further confirmed by fluorescence microscopy imaging of chromosomally-expressed AzuC C-terminally tagged with the green fluorescent protein (GFP) (Fig 2C). While wild type AzuC-GFP showed clear membrane localization, mutations replacing hydrophobic residues with charged residues $\left(\mathrm{I}_{6} \mathrm{~L}_{7}\right.$ to $\left.\mathrm{E}_{6} \mathrm{E}_{7}\right)$ 
eliminated the membrane localization. Taken together, these data support the hypothesis that AzuC is associated with the membrane as an amphipathic protein.

\section{AzuC protein interacts with GIpD}

To further investigate the role of AzuC in the cell, we carried out co-purification assays to identify interacting proteins. Cells expressing chromosomally-encoded AzuC-SPA or previouslycharacterized AcrZ-SPA (Hobbs et al., 2012) as a control were grown in M63 glucose medium. Cell lysates prepared from exponentially-growing cells were applied to calmodulin beads, and the eluants from each column were separated by SDS-PAGE (Fig 3A). Unique bands from each of the elutions were sent for mass spectrometric analysis for identification. In two independent experiments, a prominent band of $\sim 60 \mathrm{kDa}$ observed only for the AzuC-SPA cells was identified as the aerobic glycerol 3-phosphate dehydrogenase (GlpD), which catalyzes the oxidation of glycerol 3-phosphate. The most prominent band in the AcrZ sample was AcrB, a known interactor (Hobbs et al., 2012).

We tested the interaction between AzuC and GlpD, by assessing reciprocal copurification of AzuC-SPA with GlpD-HA-His 6 . Cells with chromosomally-encoded AzuC-SPA, grown to exponential phase in M63 glucose medium, were mixed with cells with chromosomally-encoded GlpD-HA-His6 grown to exponential phase in M63 glycerol medium, a condition where GlpD is known to be expressed. The mixed cells were lysed and incubated with dodecyl $\beta$-D-maltoside (DDM) to facilitate mixing of the membrane fractions. The mixed lysate was then applied to $\alpha-\mathrm{HA}$ beads, washed and eluted (Fig 3B). As controls, similar purifications were carried out by mixing the AzuC-SPA cells with cells lacking tagged proteins grown in M63 glycerol medium (Fig EV2B) or cells expressing chromosomally-encoded MgtA-HA grown in N 
medium without added $\mathrm{MgSO}_{4}$ to induce MgtA expression (Fig 3B). The eluates were analyzed for the respective tagged proteins by immunoblot analysis by using $\alpha-F L A G$ and $\alpha-H A$ antibodies. Consistent with the first purification, AzuC-SPA co-purified with GlpD-HA-His 6 and not with MgtA-HA, supporting the conclusion that GlpD is an interacting partner of AzuC. As we suggest for AzuC, GlpD has been reported to be a peripheral membrane protein that associates with the membrane through an amphipathic helix (Walz et al., 2002).

\section{AzuC protein increases GIpD activity}

Binding of AzuC to GlpD could potentially impact the stability, localization, or activity of the enzyme as has been found for other small proteins (Hobbs et al., 2012, Wang et al., 2017). To distinguish among these possibilities, we first examined the levels of chromosomally-encoded GlpD-HA-His 6 in cells transformed with $\mathrm{pKK}$, $\mathrm{pKK}-\mathrm{AzuC}$, or $\mathrm{pKK}-\mathrm{AzuC} \mathrm{L}_{\mathrm{L} 3 \mathrm{STop}}$. In the latter two plasmids, the wild type or mutant (harboring a stop codon mutation of the third codon) $a z u C$ ORF was cloned downstream of the heterologous $\mathrm{P}_{\text {tac }}$ promoter and ribosome binding site on the pKK177-3 (pKK) plasmid. Cells were grown in M63 glucose medium to $\mathrm{OD}_{600} \sim 1.0$ and then transitioned to glycerol ( $\mathrm{pH}$ 5.5) for $3 \mathrm{~h}$ given that chromosomally-expressed AzuC-SPA levels are elevated under these conditions (Fig 1B). The GlpD-HA-His 6 protein levels were similar for all three strains grown under these conditions (Fig EV3A).

To test whether AzuC affects GlpD activity, we employed a dehydrogenase activity assay in which glycerol-3-phosphate oxidation to dihydroxyacetone phosphate (DHAP) is coupled to the reduction of yellow 2-(4,5-dimethyl-2-thiazolyl)-3,5-diphenyl-2H-tetrazolium bromide (MTT) to blue formazan, which is detected at $\mathrm{OD}_{570}$ (Wegener et al., 2016). Dehydrogenase activity based on this assay was found to be almost 2-fold lower in the absence of AzuC when 
extracts were made from a WT or a $\Delta a z u C$ strain grown in M63 glucose medium and shifted to glycerol ( $\mathrm{pH} 5.5)$ for $3 \mathrm{~h}$. In contrast, overexpression of wild type $\mathrm{AzuC}$, but not $\mathrm{AzuC}_{\mathrm{L} 3 \mathrm{STOP}}$, led to an increase in the dehydrogenase activity for the extracts (Fig 4A, middle panel). To further verify that this increase was GlpD dependent, the assay was repeated in a $\Delta a z u C \Delta g l p D$ double mutant. The double mutant did not show the increase in dehydrogenase activity upon AzuC overexpression (Fig 4A, bottom panel), indicating that the interaction of the small protein AzuC with GlpD increases the dehydrogenase activity of the larger protein. Interestingly, we observed a GlpD-dependent decrease in dehydrogenase activity with the $\mathrm{pKK}-\mathrm{AzuC} \mathrm{C}_{\mathrm{L} 3 \mathrm{STOP}}$ plasmid. We think this may be due to regulatory activity of the RNA (see below). The dehydrogenase assay also was carried out with these strains shifted to M63 glycerol ( $\mathrm{pH} 7.0$ ) where we observed similar, albeit somewhat smaller, effects of $\triangle a z u C$ and AzuC overexpression on activity (Fig EV3B).

\section{AzuC overexpression causes an increase in cell length}

The substrate for GlpD, glycerol-3-phosphate, is a precursor for phospholipid biosynthesis. Thus, we wondered whether increasing the activity of GlpD by AzuC might bias the flow of glycerol3-phosphate towards glycerol metabolism rather than phospholipid biosynthesis, which could impact cell morphology. To assess this, we carried out live-cell phase contrast microscopy of cells carrying $\mathrm{pKK}, \mathrm{pKK}-\mathrm{AzuC}$ or $\mathrm{pKK}-\mathrm{AzuC} \mathrm{L}_{\mathrm{LSTOP}}(\mathrm{Fig} 4 \mathrm{~B})$. We observed AzuC overexpressing cells, but not those carrying the vector or $\mathrm{pKK}-\mathrm{AzuC} \mathrm{C}_{\mathrm{L} 3 \mathrm{STOP}}$, had an elongated morphology. The elongated morphology was similar to the morphology observed for cells upon GlpD overexpression (Fig 4B) as well as the morphology reported for cells lacking 
phosphatidylethanolamine (Rowlett et al., 2017), which comprises $\sim 75 \%$ of the membrane phospholipid.

\section{AzuC and GIpD protein levels are repressed by the FnrS small RNA}

We previously found that AzuC levels are higher under aerobic compared to anaerobic conditions (Hemm et al., 2010). Similarly, GlpD is required under aerobic conditions and is down-regulated during anaerobic growth while a second glycerol dehydrogenase, GlpABC, is required under anaerobic conditions. It was interesting to note that interactions between the anaerobic-induced sRNA FnrS and both the $a z u C$ and $g l p D$ mRNAs were found in genome-wide assays of RNA-RNA interactions on the Hfq chaperone (Melamed et al., 2020, Melamed et al., 2016). We also could predict base pairing between the $5^{\prime}$ end of FnrS and $a z u C$ as well as $g l p D$ (Fig 5A and 5C). These observations suggested possible FnrS-mediated repression of AzuC and GlpD synthesis. Consistent with this hypothesis, we observed higher AzuC-SPA levels in a $\Delta f n r S$ strain (Fig EV4A) and lower AzuC-SPA levels upon overexpression of WT FnrS and previously-generated FnrS-I and FnrS-II mutants (Durand \& Storz, 2010) but not FnrS-III for which base pairing is predicted to be disrupted (Fig 5B). We similarly observed that WT FnrS, FnrS-I and FnrS-II, but not FnrS-III repressed a azuC-lacZ translational fusion expressed from the heterologous $\mathrm{P}_{\mathrm{BAD}}$ promoter (Fig EV4B). Repression was restored for the FnrS-III mutant but not WT FnrS, FnrS-I, and FnrS-II by compensatory mutations in the azuC-lacZ-III mutant fusion demonstrating direct base-pairing between FnrS and the $a z u C$ mRNA. We also observed slightly lower levels of the GlpD-HA-His 6 protein upon overexpression of WT FnrS, FnrS-I and FnrS-II, but not FnrS-III (Fig 5D). Together these results indicate that the $5^{\prime}$ end of FnrS base pairs with the $a z u C$ and $g l p D$ mRNAs to repress synthesis of the two proteins. 


\section{AzuCR overexpression reduces growth in glycerol and galactose}

Given the AzuC effect on GlpD together with the different AzuC levels for cells grown in the presence of different carbon sources, we examined the consequences of AzuC overexpression from the $\mathrm{pKK}$ vector for growth in glucose and glycerol at $\mathrm{pH} 7.0$ and 5.5 and galactose at $\mathrm{pH}$ 7.0 (Fig 6 and Fig EV5A). For pKK-AzuC cells, but not the pKK vector control and pKK$\mathrm{AzuC}_{\mathrm{L3STOp}}$ cells, we observed a significant growth defect in M63 glycerol pH 5.5 and a partial defect in M63 glycerol pH 7.0, consistent with the larger effect of AzuC on GlpD activity in M63 glycerol pH 5.5 compared to $\mathrm{pH}$ 7.0. A similar phenotype was observed for overexpression of AzuC-SPA indicating that the tagged derivative of AzuC is functional (Fig EV5B). Growth in minimal medium with either glucose or galactose was not significantly changed by the pKKAzuC plasmid.

We also examined the effect of overexpressing the full-length $a z u C$ mRNA (pRI-AzuCR)

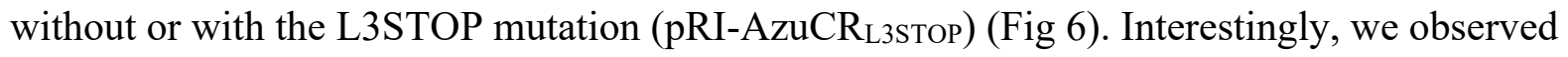
different effects on growth for these plasmids. While growth in M63 glucose $\mathrm{pH} 7.0$ was not affected, pRI-AzuCR led to a growth defect in M63 glycerol pH 7.0 and even more so at pH 5.5 as well as in M63 galactose $\mathrm{pH}$ 7.0. Contrary to the detrimental effect of the L3STOP mutation when only the $a z u C$ coding sequence was included, the L3STOP mutation in the full-length transcript still blocked growth and, in M63 glycerol pH 7.0, actually exacerbated the growth defect. This observation suggested the transcript could have a second role as a regulatory RNA, which we have denoted AzuR.

\section{AzuR functions as an sRA to repress $\mathrm{cad} A$ and $\mathrm{galE}$}


Based on our findings that the AzuCR transcript could have a second role as an sRNA, we investigated its potential as a base-pairing sRNA by searching for possible base pairing targets using TargetRNA2 (Kery et al., 2014) and IntaRNA (Mann et al., 2017) prediction programs. Given the reduced growth associated with AzuCR overexpression in cells grown in galactose and low $\mathrm{pH}$, we focused on potential target genes that might be important under these conditions. One predicted target with extensive potential base pairing was cadA, encoding lysine decarboxylase (Fig 7A). Consistent with AzuR-mediated regulation of $c a d A$, we observed decreased expression of a cadA-gfp fusion upon AzuCR overexpression and even more so for AzuCR $_{\mathrm{L} 3 \mathrm{STOP}}$ overexpression (Fig 7B). Additionally, there were higher overall levels of cadA$g f p$ expression in the $\Delta a z u C$ strain compared to the WTstrain, suggesting that chromosomallyencoded AzuC contributes to the repression. Consistent with the base pairing predicted in Fig 7A, the M1 mutations in AzuCR $\mathrm{L}_{\text {3STop }}$ reduced $c a d A-g f p$ repression, while regulation was restored when compensatory mutations were introduced in the cadA-gfp construct (Fig 7C). Another predicted target for base pairing with AzuR was galE (Fig 7D), the first gene in the galETKM galactose operon. The AzuCR $\mathrm{L}_{\text {3STOP }}$ derivative also repressed a galE-gfp fusion in both the WT and $\triangle a z u C$ backgrounds, with partial repression by AzuCR (Fig 7E). Again there is direct base pairing between AzuCR and galE, as the M2 mutations in AzuCR $\mathrm{L}_{3 \mathrm{STOp}}$ or galE alone reduced AzuCR-mediated galE-gfp repression, while repression was restored when both compensatory mutations were present (Fig 7F).

\section{AzuCR RNA association with Hfq and ProQ is not required for $\operatorname{cad} A$ repression}

Consistent with the observation that $\Delta h f q$ impacts AzuC protein levels (Fig 1B), we found that the AzuCR mRNA co-immunoprecipitates with Hfq (Fig 8A). Another RNA chaperone that has 
been found to bind to sRNA-mRNA pairs in E. coli and impacts the stability of some RNAs is ProQ (Melamed et al., 2020). As with Hfq, AzuCR co-immunoprecipitates with ProQ (Fig 8A). However, in contrast to the increased AzuCR RNA levels in the $\Delta h f q$ background, AzuCR RNA levels were decreased in the $\triangle p r o Q$ background. We wondered whether AzuCR functions as an sRNA repressor were mediated by Hfq or ProQ and examined repression of the cadA-gfp in $\Delta h f q$ and $\Delta$ pro $Q$ single as well as $\Delta h f q \Delta p r o Q$ double mutant backgrounds. GFP activity levels overall were lower when Hfq was absent, but we observed cadA-gfp repression by AzuCR L3STOP $_{\text {f }}$ overexpression in all backgrounds (Fig 8B). These observations indicate that although both Hfq and ProQ bind to AzuCR, the RNA chaperones are not required for the repression of $c a d A$ when $\mathrm{AzuCR}_{\mathrm{L} 3 \mathrm{STOP}}$ is overexpressed, possibly due to the long region of potential base pairing.

\section{AzuC translation and AzuR base pairing activity interfere}

The region of base pairing between AzuR and cadA and galE (89-107 nt relative to the transcription start) overlaps the $a z u C$ coding sequence (40-126 nt relative to the transcription start) raising the question of whether the mRNA and base pairing activities of the AzuCR RNA interfere which each other. The hypothesis that translation interferes with base pairing is supported by the observations that $\mathrm{AzuCR}_{\mathrm{L} 3 \mathrm{STOP}}$ was more effective at repressing the $\operatorname{cadA}-g f p$ and galE-gfp fusions than AzuCR (Fig 7B and 7E). To determine if base pairing activity reciprocally interfers with translation, we examined the levels of chromosomally-encoded AzuCSPA upon overexpression of the base pairing regions of $c a d A$ and galE along with control regions of these genes not predicted to base pair with AzuCR. Interestingly, no repression was observed for cells grown in M63 glucose. In contrast, the base pairing fragments, but not the control fragments, led to decreased AzuC-SPA levels for cells grown in M63 with galactose (Fig 
bioRxiv preprint doi: https://doi.org/10.1101/2021.04.27.441574; this version posted April 27, 2021. The copyright holder for this preprint (which was not certified by peer review) is the author/funder, who has granted bioRxiv a license to display the preprint in perpetuity. It is made available under aCC-BY 4.0 International license.

8C). These observations suggest that base pairing can interfere with translation, particularly when AzuC protein levels overall are low as is the case for cells grown in M63 galactose. 


\section{Discussion}

Successful adaptation to varying environmental conditions requires regulation that can rapidly lead to changes in metabolism. Along with transcription factors, sRNAs and small proteins are emerging as important regulators. While base-pairing sRNAs generally are not thought to be translated, a few have been reported to encode small proteins. Even fewer of these dual-function RNAs have been characterized. Here we report that the 164 nt RNA previously reported to encode a 28 amino acid small protein (AzuC) (Hemm et al., 2010) also functions as a regulatory RNA (AzuR). We show the AzuC protein binds and activates GlpD, an enzyme at the junction of respiration, glycolysis, and phospholipid biosynthesis (Fig 3A and 3B), while the RNA base pairs with and represses expression from the cadA and galETKM mRNAs (Fig 7).

\section{AzuCR is a unique dual-function RNA}

There are a number of features of AzuCR that are unique compared to other dual-function RNAs. First, while the regions involved in base pairing and protein coding are separate for the wellcharacterized E. coli SgrS-SgrT and Staphylococcus aureus RNAIII RNAs (reviewed in (Raina et al., 2018)), as well as the Vibrio cholerae VcdRP RNA described in a co-submitted paper (Venkat et al., 2021), the region of AzuCR involved in base pairing with the cadA and galE targets overlaps the $a z u C$ coding sequence (Fig 1A). Another notable feature of this dualfunction RNA is that while the gene is not broadly conserved, the levels of the RNA and protein are highly regulated. In our previous study, we observed the AzuC protein accumulates in minimal glucose medium as well as in response to low $\mathrm{pH}$, high temperature, and hydrogen peroxide, while the levels are low under anaerobic conditions (Hemm et al., 2010). The regulation in response to glucose availability was shown to be at the transcriptional level via 
CRP derepression. In our current study, we show that AzuC repression under anaerobic conditions is mediated by the Hfq-dependent sRNA FnrS, which base pairs near the AzuC ribosome binding site (Fig 5A). To the best of our knowledge, FnrS regulation of AzuCR is the first example of another sRNA regulating the translation of a dual-function RNA. The observation that AzuC levels are higher in $\Delta h f q$ compared to $\Delta f n r S$ mutant cells (Fig EV4A) suggests that other Hfq-dependent sRNAs might repress AzuC synthesis. This is further indicated by the discordance between RNA and protein levels under some conditions (Fig 1B). Consistent with the discordant expression of the AzuCR RNA compared to the AzuC protein, we found that the small protein and base pairing activities modulate overlapping but distinct pathways; AzuC plays a role in glycerol metabolism (Fig 3 and 4) and AzuCR impacts galactose and glycerol metabolism (Fig 6). The regulation of different pathways by the two activities of AzuCR contrasts with SgrST RNA where the SgrT protein and the base-pairing SgrS RNA both down-regulate the PtsG glucose transporter activity.

\section{AzuC stimulation of GlpD activity}

Although the functions of only a few small proteins have been described, most are inhibitory (reviewed in (Storz et al., 2014)). Thus, AzuC is unusual in that it increases GlpD activity. GlpD, one of the key flavin-linked primary dehydrogenases of the respiratory electron transport chain, catalyzes the oxidation of glycerol-3-phosphate to DHAP (Yeh et al., 2008). GlpD exists in in both soluble and membrane-bound forms and is only fully active when the enzyme is associated with the cytoplasmic membrane through lipid-enzyme interactions or when reconstituted with phospholipids in vitro (Yeh et al., 2008, Schryvers et al., 1978, Robinson \& Weiner, 1980).

Interestingly, GlpD activity was previously reported to be increased by amphipaths (Robinson \& 
Weiner, 1980). Like GlpD, AzuC is an amphipathic protein localized to the cytoplasmic membrane (Fig 2). Thus, it is possible that AzuC promotes GlpD binding to the cytoplasmic membrane. AzuC also could change the stability of GlpD, though we did not observe obvious differences in protein levels (Fig EV3A). Alternatively, AzuC could increase GlpD activity by causing a conformational change. Interestingly, the 29 amino acid $V$. cholerae VcdP similarly was found to increase citrate synthase activity, likely by counteracting the inhibitory effects of NADH (Venkat et al., 2021).

The physiological role of AzuC activation of GlpD, particularly at $\mathrm{pH} 5.5$, is an interesting question. We suggest AzuC binds GlpD under acidic conditions to modulate the levels of glycerol-3-phosphate, which can undergo two acylation steps to form phosphatidic acid, a precursor for the phospholipids phosphatidylethanolamine (PE), phosphatidylglycerol (PG) and cardiolipin (CL). Bacterial adaptation to environmental stress can be accompanied by changes in the lipopolysaccharide (LPS) structure, the phospholipid composition, and the protein content of the inner and outer membranes (Rowlett et al., 2017). These changes in turn impact cell division, energy metabolism, osmoregulation as well as resistance to cationic antimicrobial peptides (CAMPs). In support of the hypothesis that AzuC activation of GlpD affects membrane composition, we observed that cells overexpressing AzuC or GlpD grown in low pH showed increased cell length (Fig 4B) and reduced growth (Fig 6), phenotypes that have also been observed in cells lacking the phospholipids PE and PG/CL (Rowlett et al., 2017).

\section{AzuR repression of the $\operatorname{cad} A$ and the galETKM mRNAs}

We found that as a base pairing RNA, AzuR represses expression of CadA (Fig 7A, B, and C), which is induced under acidic growth conditions and confers resistance to weak organic acids 
produced during carbohydrate fermentation under anaerobiosis and phosphate starvation (reviewed in (Kanjee \& Houry, 2013)). This regulation could partially explain the growth defect for cells growing in glycerol pH 5.5 observed upon AzuCR overexpression with and without a stop codon (Fig 6). We also identified galETKM mRNA as another direct AzuR target (Fig 7D, $\mathrm{E}$, and F). Consistent with this regulation, we see a drastic growth defect with galactose as the sole carbon source upon overexpression of AzuCR with and without a stop codon (Fig 6). While AzuR base pairs near the ribosome binding site of the cadA mRNA likely blocking ribosome binding, the base pairing with the galETKM mRNA is internal to the galE coding sequence. We suggest that for this mRNA, base pairing may lead to changes in mRNA stability or alternatively the Rho-dependent transcription termination reported for the galETKM mRNA (Wang et al., 2014). Since we also observe an RNA-dependent growth phenotype for cells grown in glycerol $\mathrm{pH}$ 7.0, we suggest that AzuR might target other genes, particularly genes related to glycerol metabolism.

\section{Competition between two AzuCR activities}

Several of our experiments indicate that there is competition between the mRNA and base pairing activities of AzuCR. We observed that a stop codon blocking translation improves AzuR base pairing activity (Fig 7B and 7E) and overexpression of fragments of the base pairing targets cadA and galE inhibits AzuC translation (Fig 8C). The conflict between base pairing and translation raises intriguing questions about what activity predominates under different growth conditions, whether the RNA can transition from one function to the other, what factors determine which activity predominates, and how the two activites evolved. We suggest that there are a number of scenarios for how AzuCR could act. There may be conditions where AzuCR acts 
solely a riboregulator and other conditions where AzuCR is solely an mRNA. There also may be conditions where there are two populations of AzuCR, some transcripts acting as an sRNA and others being translated. Additionally, AzuCR could first act as an mRNA and subsequently go on to act as a riboregulator.

The factors that regulate the distribution of AzuCR between these regulatory roles are not fully understood but clearly depend on the levels of the AzuCR RNA, sRNAs that repress AzuC translation, the levels of the mRNA targets of AzuCR, the levels of the Hfq and ProQ chaperones and likely other factors. The observed FnrS-dependent repression of AzuC synthesis is at least partially dependent on Hfq, while the stability of the RNA appears to depend on ProQ. The finding that AzuCR may only be a base-pairing RNA under specific conditions raises caveats for global approaches such as RIL-seq (Melamed et al., 2016) or RNA-seq after pulse overexpression for identifying sRNA targets and function. If these experiments are carried out under conditions where translation predominates, the effects of the base pairing activity may not be detected. These questions about AzuCR likely are relevant for other dual-function RNAs and are important directions for future research. 


\section{Materials and Methods}

\section{Bacterial strains and plasmid construction}

Bacterial strains, plasmids, and oligonucleotides used in this study are listed in Appendix Tables S1, S2 and S3, respectively. E. coli strains are derivatives of wild-type MG1655 (F- lambda$i l v G-r f b-50 r p h-1)$. Tagged strains were generated by $\lambda$ Red-mediated recombineering (Yu et al., 2000) using NM400 and the oligonucleotides listed in Appendix Table S3. pJL148 (Zeghouf et al., 2004) was used as the template to amplify the SPA tag. The chromosomal $\mathrm{P}_{\mathrm{BAD}^{-}}$ 5'UTR ${ }_{a z u C}-l a c Z$ and $\mathrm{P}_{\mathrm{BAD}}-5^{\prime} \mathrm{UTR}_{a z u C}$-lacZ III fusions (carrying the first $87 \mathrm{nt}$ of the $a z u C$ mRNA fused to the seventh codon of the lac $Z$ coding sequence) were created by carrying out PCR using primers listed in Appendix Table S3 to applify the desired region of $a z u C$ followed by integration of the product into the chromosome of PM1205 (Mandin \& Gottesman, 2009). Alleles marked by antibiotic markers were moved between strains by P1 transduction. When necessary, kanamycin resistance cassettes were excised from the chromosome by FLP-mediated recombination using the FLP recombinase encoded on pCP20 (Cherepanov \& Wackernagel, 1995). All plasmids are derivatives of pAZ3 (Kawano et al., 2005), pKK177-3 (Brosius \& Holy, 1984), pRI (Opdyke et al., 2004), pBRplac (Guillier \& Gottesman, 2006) or pXG10-SF (Corcoran et al., 2012). All chromosomal mutations and fusions and plasmid inserts were confirmed by sequencing.

\section{Bacterial growth}

Cells were grown in Luria-Bertani broth (LB) or M63 minimal media supplemented with $0.001 \%$ vitamin B1 and glucose, glycerol or galactose $(0.2 \%, 0.4 \%$ or $0.2 \%$, respectively). For some experiments, M63 medium was buffered to pH 5.5 with $100 \mathrm{mM}$ MES. Cells were grown to the 
indicated $\mathrm{OD}_{600}$ after a 1:100 dilution of the overnight culture grown in LB, except for all M63 glycerol, pH 5.5 samples, where overnight cultures were grown in M63 glycerol, pH 5.5. Where indicated, media contained antibiotics with the following concentrations: ampicillin $(100 \mu \mathrm{g} / \mathrm{ml})$, chloramphenicol $(25 \mu \mathrm{g} / \mathrm{ml})$ and kanamycin $(30 \mu \mathrm{g} / \mathrm{ml})$.

\section{Immunoblot analysis}

The cell pellet from $1 \mathrm{ml}$ of cells grown in the indicated medium was resuspended in $1 \mathrm{X}$ PBS (KD Medical), $7 \mu$ of $2 X$ Laemmli buffer (BioRad) and $2 \mu$ of $\beta$-mercaptoethanol, and $10 \mu 1$ were loaded on a Mini-PROTEAN TGX 5\%-20\% Tris-Glycine gel (Bio-Rad) and run in 1 X Tris Glycine-SDS (KD Medical) buffer. The proteins were electro-transferred to nitrocellulose membranes (Invitrogen) for $1 \mathrm{~h}$ at $100 \mathrm{~V}$. Membranes were blocked with 5\% non-fat milk (BioRad) in 1X PBS with $0.1 \%$ of Tween 20 (PBS-T) for $1 \mathrm{~h}$ and probed with a 1:3,000 dilution of $\alpha$-FLAG-HRP antiserum (Sigma), 1:1,000 dilution of $\alpha$-AzuC antiserum (New England Peptide); 1:1,000 dilution of $\alpha$-His-HRP antiserum (Qiagen), or 1:1,000 dilution of $\alpha$-OmpA antiserum (Antibody Research Corporation) in the same PBS-T buffer with 5\% milk for $1 \mathrm{~h}$. After the incubation with the $\alpha$-AzuC and $\alpha$-OmpA antiserum, membranes were incubated with a 1:2,000 dilution of HRP-labelled anti-rabbit antibody (Life Technologies). All blots were washed 4X with PBS-T and then developed with a Amersham ECL Western Blotting Detection Kit (GE Healthcare).

\section{Total RNA isolation}

Cells corresponding to the equivalent of $10 \mathrm{OD}_{600}$ were collected by centrifugation, and snap frozen in liquid nitrogen. RNA was extracted according to the standard TRIzol (Thermo Fisher 
Scientific) protocol. Briefly, $1 \mathrm{ml}$ of room temperature TRIzol was add to cell pellets, resuspended thoroughly to homogenization, and incubated for $5 \mathrm{~min}$ at room temperature. After the addition of $200 \mu 1$ of chloroform and thorough mixing by inversion, samples were incubated for $10 \mathrm{~min}$ at room temperature. After samples were centrifuged for $10 \mathrm{~min}$ at $4^{\circ} \mathrm{C}$ on maximal speed, the upper phase $(\sim 0.6 \mathrm{ml})$ was transferred into a new tube and $500 \mu \mathrm{l}$ of isopropanol was added. Samples again were mixed thoroughly by inversion, incubated for $10 \mathrm{~min}$ at room temperature and centrifuged at maximal speed for 15 min at $4^{\circ} \mathrm{C}$. RNA pellets were washed twice with $75 \%$ ethanol and then dried at room temperature. RNA was resuspended in 20-50 $\mu 1$ of DEPC water and quantified using a NanoDrop (Thermo Fisher Scientific).

\section{Northern analysis}

Total RNA (5-10 $\mu \mathrm{g}$ per lane) was separated on denaturing 8\% polyacrylamide gels containing 6 M urea (1:4 mix of Ureagel Complete to Ureagel-8 (National Diagnostics) with $0.08 \%$ ammonium persulfate in $1 \mathrm{X} \mathrm{TBE}$ buffer at $300 \mathrm{~V}$ for $90 \mathrm{~min}$. The RNA was transferred to a Zeta-Probe GT membrane (Bio-Rad) at $20 \mathrm{~V}$ for $16 \mathrm{~h}$ in $0.5 \mathrm{X}$ TBE, UV-crosslinked, and probed with ${ }^{32}$ P-labeled oligonucleotides (Listed in Table 1) in ULTRAhyb-Oligo buffer (Ambion Inc.) at $45^{\circ} \mathrm{C}$. Membranes were rinsed twice with $2 \mathrm{X}$ SSC- $0.1 \%$ SDS at room temperature, once with $0.2 \mathrm{X}$ SSC-0.1\% SDS at room temperature, washed for 25 min with $0.2 \mathrm{X}$ SSC- $0.1 \%$ SDS at $45^{\circ} \mathrm{C}$, followed by a final rinse with $0.2 \mathrm{XSC}-0.1 \% \mathrm{SDS}$ at room temperature before autoradiography was performed with HyBlot CL film (Denville Scientific Inc.).

\section{Sub-cellular fractionation}


Cells with chromosomally-encoded AzuC-SPA were grown in the indicated medium at $37^{\circ} \mathrm{C}$ to an $\mathrm{OD}_{600} \sim 0.3$, centrifuged at $20,000 \times \mathrm{g}$ for $10 \mathrm{~min}$ at $4^{\circ} \mathrm{C}$, resuspended in fractionation buffer (1/20 vol of 20\% sucrose, $50 \mathrm{mM}$ Tris $\mathrm{pH} 8)$ with $1 \mathrm{mM}$ EDTA and $0.1 \mathrm{mg} / \mathrm{ml}$ lysozyme, and then incubated $1 \mathrm{~h}$ at $25^{\circ} \mathrm{C}$ with gentle shaking. After the cells were centrifuged at $20,000 \times \mathrm{g}$ for $15 \mathrm{~min}$ at $4^{\circ} \mathrm{C}$, the top periplasmic fraction was removed. The pellet fraction was resuspended in water to lyse the spheroplasts. The resulting crude lysate was passed through a 30 -gauge syringe needle $6 \mathrm{X}$ to homogenize the sample and reduce viscosity. The lysate was then clarified by centrifugation at $20,000 \times \mathrm{g}$ for $5 \mathrm{~min}$ at $4^{\circ} \mathrm{C}$. This was repeated $3 \mathrm{X}$. A $500 \mu 1$ of the clarified lysate was layered on top of a $500 \mu$ l-sucrose cushion ( 5 mM EDTA and $1.4 \mathrm{M}$ sucrose. Samples were centrifuged at $130,000 \times \mathrm{g}$ for $2 \mathrm{~h}$ at $4^{\circ} \mathrm{C}$ in a TLA100.3 rotor (Beckman Optima TLX table top centrifuge). Following centrifugation, $425 \mu 1$ was carefully removed from the top layer (soluble fraction). Then, the interface and remaining liquid were removed (inner membrane fraction). The pelleted material was resuspended in $500 \mu 1$ of fractionation buffer (pellet fraction). SDS was added to all fractions (final concentration 1\%) and the samples were incubated overnight at room temperature. Equal volumes of fractions were assayed by immunoblotting with $\alpha$-FLAG-HRP and $\alpha$-OmpA antibody.

Cells expressing AzuC from a plasmid were grown as above, collected by centrifugation at $4 \mathrm{~K} \mathrm{rpm}$ for $10 \mathrm{~min}$ at $4^{\circ} \mathrm{C}$, resuspended as above but incubated $10 \mathrm{~min}$ on ice. After the lysate was incubated as above the periplasmic fraction removed, the pellet was resuspended in $1 \mathrm{ml}$ of 20\% sucrose, $50 \mathrm{mM}$ Tris $\mathrm{pH} 8$ and sonicated with a Sonic Dismembrator Model 100 (Fisher Scientific) $3 X$ for $5 \mathrm{sec}$ at power setting 4. Samples were centrifuged $3 X$ at $12,000 \times \mathrm{g}$ for $5 \mathrm{~min}$ at $4^{\circ} \mathrm{C}$ to remove unlysed cells. The supernatant was then centrifuged at $56 \mathrm{~K} \mathrm{rpm}$ for $1 \mathrm{~h}$ at $4^{\circ} \mathrm{C}$ in a Beckman TLA100.3 rotor. The supernatant containing the cytoplasmic fraction was removed 
and the pellet containing the membrane fraction was resuspended in $1 \mathrm{ml}$ of $20 \%$ sucrose, $10 \mathrm{mM}$ Tris $\mathrm{pH} 8$ by sonication. Equal volumes of fractions were assayed by immunoblotting with polyclonal $\alpha$-AzuC antibody.

\section{Microscopy}

Cells grown as indicated were harvested, resuspended in phosphate buffered saline (PBS) (KD Medical) and placed on lysine-coated glass bottom dish (Mattek Corporation). Cells were fixed by applying a $1 \%$ agarose pad on top of the sample with gentle pressure. Cells were viewed with a DeltaVision Core microscope system (Applied Precision) equipped with an environmental control chamber. Bright field and fluorescence images were captured with a Photometrics CoolSnap HQ2 camera. Seventeen planes were acquired every $0.2 \mu \mathrm{m}$ at $22^{\circ} \mathrm{C}$, and the data were deconvolved using SoftWorx software (GE Healthcare).

\section{Purification of chromosomally-encoded AzuC-SPA}

Cells expressing AzuC-SPA (GSO351) cells grown in LB at $37^{\circ} \mathrm{C}$ overnight culture were diluted 1:100 into 11 of M63 glucose minimal media and incubated at $37^{\circ} \mathrm{C}$. At $\mathrm{OD}_{600} \sim 1.0$, cells were collected by centrifugation $(4,650 \times \mathrm{g}, 20 \mathrm{~min})$. The pellet was resuspended in $20 \mathrm{ml}$ of TNG buffer [10 mM Tris (pH 7.5), $100 \mathrm{mM} \mathrm{NaCl,} \mathrm{10 \%} \mathrm{glycerol]} \mathrm{supplemented} \mathrm{with} \mathrm{Protease}$ Inhibitor Cocktail (Roche). The cells were lysed using a microfluidizer processor (Microfluidics) at 20,000 psi, and the insoluble cellular debris was removed by centrifugation $(20,000 \times \mathrm{g}, 30$ min). The cleared lysate was incubated with $50 \mathrm{mM}$ dodecyl $\beta$-D-maltoside (DDM) at $4^{\circ} \mathrm{C}$ for 2 h. Next, the DDM-supplemented lysate was incubated with $500 \mu 1$ of calmodulin-sepharose beads (Amersham Biosciences) overnight at $4^{\circ} \mathrm{C}$. The lysate and beads were applied to a Bio- 
Spin disposable chromatography column (Bio-Rad Laboratories) and allowed to drain by gravity.

The calmodulin column was washed $15 \mathrm{ml}$ of TNG buffer with $2 \mathrm{mM}$ DDM, $5 \mathrm{mM} \beta-\mathrm{ME}$, and 2 $\mathrm{mM} \mathrm{CaCl}$. Finally, proteins were eluted from the calmodulin column in $1 \mathrm{ml}$ TNG buffer supplemented with $4 \mathrm{mM}$ EDTA, $5 \mathrm{mM} \beta-\mathrm{ME}$, and 2.5\% SDS. To analyze the protein samples, $7.5 \mu 1$ of $2 \mathrm{X}$ Laemmli buffer was added to $21 \mu \mathrm{l}$ of each sample. The samples were heated at $95^{\circ} \mathrm{C}$ for $5 \mathrm{~min}$, and aliquots were subjected to SDS/PAGE in a 10-20\% Tris-glycine gel (Invitrogen) at $12 \mathrm{~V} / \mathrm{cm}$. Proteins were visualized with Coomassie Blue Stain. Bands of interest were excised from the gel and analyzed by liquid chromatography-tandem mass spectrometry (LC-MS/MS). An identical purification was carried out for cells with chromosomal acrZ-SPA (GSO350) grown in 11 of LB to $\mathrm{OD}_{600} \sim 0.6$.

\section{Purification of chromosomally-encoded GIpD-HA-His 6 and MgtA-HA}

MG1655 cells or cells expressing AzuC-SPA (GSO351), GlpD-HA-His (GSO1011) or the control MgtA-HA (GSO785) from the chromosome grown in $\mathrm{LB}$ at $37^{\circ} \mathrm{C}$ for $16 \mathrm{~h}$, were diluted 1:100 into 11 of M63 glucose minimal medium, M63 glycerol minimal medium or N medium with $500 \mu \mathrm{M} \mathrm{MgSO}_{4}$, respectively and incubated at $37^{\circ} \mathrm{C}$. The WT strain and strains expressing GlpD-HA-His6 and AzuC-SPA were grown to $\mathrm{OD}_{600} \sim 1.0$. The strains expressing MgtA-HA were grown to $\mathrm{OD}_{600} \sim 0.4-0.6$, collected, washed $2 \mathrm{X}$ in $\mathrm{N}$ medium without added $\mathrm{MgSO}_{4}$, resuspended in $\mathrm{N}$ medium without added $\mathrm{MgSO}_{4}$ and grown for another $2.5 \mathrm{~h}$ to induce MgtAHA expression. For all cultures, cells were collected by centrifugation $(4,650 \times \mathrm{g}, 20 \mathrm{~min})$ and resuspended in $15 \mathrm{ml}$ of TNG buffer supplemented with Protease Inhibitor Cocktail (Roche). Cells from the SPA tagged protein cultures were mixed with the control WT or HA-tagged protein cultures at a 1:1 ratio. To ensure thorough mixing, cells were shaken gently at $4^{\circ} \mathrm{C}$ for 15 
min. The cells were then homogenized as for the SPA-tagged protein purification and incubated with $50 \mathrm{mM}$ DDM in $4^{\circ} \mathrm{C}$ for $2 \mathrm{~h}$. The insoluble cellular debris was removed by centrifugation $(20,000 \times \mathrm{g}, 20 \mathrm{~min})$. Subsequently, the supernatant was applied to $100 \mu \mathrm{L}$ of Pierce $\alpha-\mathrm{HA}$ magnetic beads (Thermo Scientific) in a $50 \mathrm{ml}$ tube and incubated overnight at $4^{\circ} \mathrm{C}$. Beads were collected with a MagneSphere technology magnetic separation stand (Promega) and resuspended in $1 \mathrm{ml}$ of TNG buffer. The beads were washed with $1 \mathrm{ml}$ of TNG buffer (10X). The beads were then resuspended in 1 XPBS $(50 \mu \mathrm{l})$ and $2 \mathrm{X}$ Laemmli buffer $(50 \mu \mathrm{l})$ and heated at $95^{\circ} \mathrm{C}$ for $5 \mathrm{~min}$. Samples $(15 \mu \mathrm{l})$ were analyzed on immunoblots using $\alpha$-His or M2 $\alpha$-FLAG antibodies.

\section{Dehydrogenase activity assay}

Cells were grown in M63 glucose minimal medium to $\mathrm{OD}_{600} \sim 1.0$. Cells were pelleted and washed with M63 glycerol medium, $\mathrm{pH} 7.0$ or pH 5.5. Cells were then resuspended in same volume of the same medium and grown at $37^{\circ} \mathrm{C}$ for $3 \mathrm{~h}$. Cells $(500 \mu \mathrm{l})$ were pelleted and resuspended in $500 \mu \mathrm{l}$ of lysis buffer (25 mM Tris- $\mathrm{HCl}, 10 \mathrm{mM} \mathrm{NaCl}$ and $0.4 \%$ Triton X100). Cells were lysed by adding $0.6 \mathrm{~g}$ of glass beads and vortexing $30 \mathrm{~s}$ followed by $30 \mathrm{~s}$ incubation on ice, repeated $5 \mathrm{X}$. The cells were then centrifuged at $20,000 \times \mathrm{g}$ for $2 \mathrm{~min}$ at $4^{\circ} \mathrm{C}$, and the lysate was used to measure the dehydrogenase activity. A method monitoring MTT reduction to quantitate the dehydrogenase activity of GlpD (Yeh et al., 2008) was modified as follows. Each $225 \mu 1$ microcuvette contained the following: $25 \mathrm{mM}$ Tris/ $\mathrm{HCl} \mathrm{pH} 7.4,100 \mathrm{mM} \mathrm{NaCl}, 1 \mathrm{mM}$ MTT (Sigma Aldrich), $3 \mathrm{mM}$ phenazine methosulfate (PMS, Sigma Aldrich) and $100 \mu \mathrm{l}$ of lysate. This was used as the blank, and the reaction was initiated by the addition of $3.7 \mathrm{mM} s n$ glycerol-3-phosphate (Sigma Aldrich). The reduction of MTT at $570 \mathrm{~nm}$ was continuously monitored on a BMG LABTECH plate reader for $118 \mathrm{~min}$ at room temperature. 


\section{$\beta$-galactosidase assays}

Cultures were grown in $\mathrm{LB}$ to $\mathrm{OD}_{600} \sim 1.0$ with arabinose $(0.2 \%) .100 \mu 1$ of cells were added to $700 \mu \mathrm{l}$ of $\mathrm{Z}$ buffer $\left(60 \mathrm{mM} \mathrm{Na}_{2} \mathrm{HPO}_{4}, 40 \mathrm{mM} \mathrm{NaH}_{2} \mathrm{PO}_{4}, 10 \mathrm{mM} \mathrm{KCl}, 1 \mathrm{mM} \mathrm{MgSO} 4,50 \mathrm{mM} \beta-\right.$ mercaptoethanol). After the addition of $15 \mu 1$ of freshly-prepared $0.1 \%$ SDS and $30 \mu 1$ of chloroform, each sample was vortexed for $30 \mathrm{~s}$ and then incubated at room temperature for 15 min to lyse the cells. The assay was initiated by adding $100 \mu 1$ of ONPG (4 mg/ml). The samples were incubated at room temperature until the reaction was terminated by the addition of $500 \mu 1$ of $1 \mathrm{M} \mathrm{Na}_{2} \mathrm{CO}_{3} . \mathrm{A}_{420}$ and $\mathrm{A}_{550}$ values determined with a spectrophotometer were used to calculate Miller units.

\section{Growth curves}

Colonies of $\Delta a z u C: \because k a n$ (GSO193) transformed with pRI, pRI-AzuCR, pRI-AzuCRL3STop, pKK, $\mathrm{pKK}-\mathrm{AzuC}$ or $\mathrm{pKK}-\mathrm{AzuC} \mathrm{L}_{\mathrm{L} \text { Stop }}$ grown on $\mathrm{LB}$ plates were inoculated into glucose $(\mathrm{pH} 7.0)$, glycerol ( $\mathrm{pH} 7.0$ and 5.5), and galactose $(\mathrm{pH} 7.0)$ and allowed to grow overnight at $37^{\circ} \mathrm{C}$, at which point all cultures were in stationary phase. Cultures were diluted to $\mathrm{OD}_{600} \sim 0.05$ (time 0) in $25 \mathrm{ml}$ of the same media and grown at $37^{\circ} \mathrm{C}$. $\mathrm{OD}_{600}$ was measured at $16 \mathrm{~h}$ or growth was followed for $29 \mathrm{~h}$.

\section{GFP reporter assay}

The GFP reporter assay was principally done as described previously (Corcoran et al., 2012, Urban \& Vogel, 2009). WT or $\Delta a z u C:: k a n$ (GSO193) cells were transformed with a cadA-gfp, cadA-gfp-M1, galE-gfp or galE-gfp-M2 reporter plasmid and a pRI-AzuCR, pRI-AzuCR L3STop, $_{\text {, }}$ 


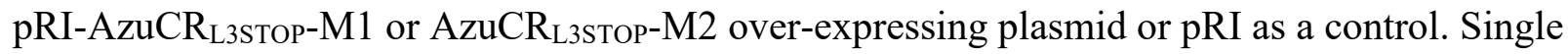
colonies were grown overnight at $37^{\circ} \mathrm{C}$ in LB supplemented with ampicillin and chloramphenicol. The cultures were diluted to $\mathrm{OD}_{600} \sim 0.05$ in fresh medium and grown at $37^{\circ} \mathrm{C}$ for $3 \mathrm{~h}$ in a 96 deep-well plate. An aliquot $(1 \mathrm{ml})$ of each culture was centrifuged and the pellet was resuspended in $220 \mu 1$ of $1 \mathrm{X}$ PBS. Fluorescence was measured using the CytoFLEX Flow Cytometer (Beckman Coulter). Three biological repeats were analyzed for every sample.

\section{Hfq and ProQ co-immunoprecipitation assays}

Cell extracts were prepared from MG1655 cells grown in M63 glucose medium to $\mathrm{OD}_{600} \sim 0.5$. Cells corresponding to the equivalent of $20 \mathrm{OD}_{600}$ were collected, and cell lysates were prepared by vortexing with 212-300 $\mu \mathrm{m}$ glass beads (Sigma-Aldrich) in a final volume of $1 \mathrm{ml}$ lysis buffer (20 mM Tris-HC, pH 8.0, $150 \mathrm{mM} \mathrm{KCl,} 1 \mathrm{mM} \mathrm{MgCl} 2,1 \mathrm{mM}$ DTT). Immunoprecipitations were carried according to (Zhang et al., 2002) using $100 \mu \mathrm{l}$ of Hfq antiserum (Zhang et al., 2002) or $100 \mu \mathrm{l}$ of ProQ antiserum (Melamed et al., 2020), $120 \mathrm{mg}$ of protein-A-sepharose (Amersham Biosciences, Piscataway, NJ) and $950 \mu \mathrm{l}$ of cell extract per immunoprecipitation reaction. Immunoprecipitated RNA was isolated from immunoprecipitated pellets by extraction with phenol:chloroform:isoamyl alcohol (25:24:1, pH 8), followed by ethanol precipitation. Total RNA was isolated from $50 \mu \mathrm{l}$ of cell lysate by Trizol (Thermo Fisher Scientific) extraction followed by chloroform extraction and isopropanol precipitation. Total and co-IP RNA samples were resuspended in $20 \mu \mathrm{l}$ of DEPC $\mathrm{H}_{2} \mathrm{O}$ and $2 \mu \mathrm{g}$ of total RNA or $200 \mathrm{ng}$ of IP RNA was subjected to Northern analysis as described below. 


\section{Acknowledgements}

We thank P. Backlund for carrying out mass spectrometry in the Eunice Kennedy Shriver National Institute of Child Health and Human Development core, A. Zhang for assistance with the co-immunoprecipitation assays, T. Updegrove for assistance with microscopy, A. Buskirk for the $a z u C$ browser image, and M. Hemm, N. Soltanzad, L. Stamper and A. Romero for help with initial experiments, and members of the Storz group for comments on the manuscript. This research was supported by the Intramural Research Program of the Eunice Kennedy Shriver National Institute of Child Health and Human Development.

\section{Author contributions}

Studies were planned by all authors and carried out by MR, JA, SB and BJP. MR, JA and GS prepared the manuscript.

\section{Conflict of interest}

The authors declare that they have no conflict of interest.

\section{References}

Brosius, J., and Holy, A. (1984) Regulation of ribosomal RNA promoters with a synthetic lac operator. Proc. Natl. Acad. Sci. USA 81: 6929-6933.

Chen, S., Lesnik, E.A., Hall, A.T., Sampath, R., Griffey, R.H., Ecker, D.J., and Blyn, L.B. (2002) A bioinformatics based approach to discover small RNA genes in the Escherichia coli genome. BioSystems 65: 157-177.

Cherepanov, P.P., and Wackernagel, W. (1995) Gene disruption in Escherichia coli: TcR and $\mathrm{KmR}$ cassettes with the option of Flp-catalyzed excision of the antibiotic-resistance determinant. Gene 158: 9-14. 
Corcoran, C.P., Podkaminski, D., Papenfort, K., Urban, J.H., Hinton, J.C., and Vogel, J. (2012) Superfolder GFP reporters validate diverse new mRNA targets of the classic porin regulator, MicF RNA. Mol. Microbiol. 84: 428-445.

Durand, S., and Storz, G. (2010) Reprogramming of anaerobic metabolism by the FnrS small RNA. Mol. Microbiol. 75: 1215-1231.

Durica-Mitic, S., Göpel, Y., and Görke, B. (2018) Carbohydrate utilization in bacteria: making the most out of sugars with the help of small regulatory RNAs. Microbiol. Spectr. 6: doi:

10.1128/microbiolspec.RWR-0013-2017.

Fontaine, F., Fuchs, R.T., and Storz, G. (2011) Membrane localization of small proteins in Escherichia coli. J. Biol. Chem. 286: 32464-32474.

Friedman, R.C., Kalkhof, S., Doppelt-Azeroual, O., Mueller, S.A., Chovancová, M., von Bergen, M., and Schwikowski, B. (2017) Common and phylogenetically widespread coding for peptides by bacterial small RNAs. BMC Genomics 18: 553.

Guillier, M., and Gottesman, S. (2006) Remodelling of the Escherichia coli outer membrane by two small regulatory RNAs. Mol. Microbiol. 59: 231-247.

Hemm, M.R., Paul, B.J., Miranda-Rios, J., Zhang, A., Soltanzad, N., and Storz, G. (2010) Small stress response proteins in Escherichia coli: proteins missed by classical proteomic studies. $J$. Bacteriol. 192: 46-58.

Hemm, M.R., Paul, B.J., Schneider, T.D., Storz, G., and Rudd, K.E. (2008) Small membrane proteins found by comparative genomics and ribosome binding site models. Mol. Microbiol. 70: 1487-1501.

Hemm, M.R., Weaver, J., and Storz, G. (2020) Escherichia coli small proteome. EcoSal Plus 9: ESP-0031-2019.

Hobbs, E.C., Yin, X., Paul, B.J., Astarita, J.L., and Storz, G. (2012) Conserved small protein associates with the multidrug efflux pump AcrB and differentially affects antibiotic resistance. Proc. Natl. Acad. Sci. USA 109: 16696-16701.

Holmqvist, E., and Vogel, J. (2018) RNA-binding proteins in bacteria. Nat. Rev. Microbiol. 16: 601-615.

Kanjee, U., and Houry, W.A. (2013) Mechanisms of acid resistance in Escherichia coli. Annu. Rev. Microbiol. 67: 65-81.

Kawano, M., Reynolds, A.A., Miranda-Rios, J., and Storz, G. (2005) Detection of 5' and 3' UTRderived small RNAs and cis-encoded antisense RNAs in Escherichia coli. Nucleic Acid Res. 33: 1040-1050.

Kery, M.B., Feldman, M., Livny, J., and Tjaden, B. (2014) TargetRNA2: identifying targets of small regulatory RNAs in bacteria. Nucleic Acid Res. 42: W124-129. 
Lloyd, C.R., Park, S.Y., Fei, J., and Vanderpool, C.K. (2017) The small protein SgrT controls transport activity of the glucose-specific phosphotransferase system. J. Bacteriol. 199: pii: e00869-00816.

Madeira, F., Park, Y.M., Lee, J., Buso, N., Gur, T., Madhusoodanan, N., Basutkar, P., Tivey, A.R.N., Potter, S.C., Finn, R.D., and Lopez, R. (2019) The EMBL-EBI search and sequence analysis tools APIs in 2019. Nucleic Acids Res. 47: W636-W641.

Mandin, P., and Gottesman, S. (2009) A genetic approach for finding small RNAs regulators of genes of interest identifies RybC as regulating the DpiA/DpiB two-component system. Mol.

Microbiol. 72: 551-565.

Mann, M., Wright, P.R., and Backofen, R. (2017) IntaRNA 2.0: enhanced and customizable prediction of RNA-RNA interactions. Nucleic Acid Res. 45: W435-W439.

Melamed, S., Adams, P.P., Zhang, A., Zhang, H., and Storz, G. (2020) RNA-RNA interactomes of ProQ and Hfq reveal overlapping and competing roles. Mol. Cell 77: 411-425.

Melamed, S., Peer, A., Faigenbaum-Romm, R., Gatt, Y.E., Reiss, N., Bar, A., Altuvia, Y., Argaman, L., and Margalit, H. (2016) Global mapping of small RNA-target interactions in bacteria. Mol. Cell 63: 884-897.

Meydan, S., Marks, J., Klepacki, D., Sharma, V., Baranov, P.V., Firth, A.E., Margus, T., Kefi, A., Vázquez-Laslop, N., and Mankin, A.S. (2019) Retapamulin-assisted ribosome profiling reveals the alternative bacterial proteome. Mol. Cell 74: 481-493.

Mól, A.R., Castro, M., S. , and Fontes, W. (2019) NetWheels: A web application to create high quality peptide helical wheel and net projections. bioRxiv 416347: doi:

https://doi.org/10.1101/416347

Olejniczak, M., and Storz, G. (2017) ProQ/FinO-domain proteins: another ubiquitous family of RNA matchmakers? Mol. Microbiol. 104: 905-915.

Opdyke, J.A., Kang, J.-G., and Storz, G. (2004) GadY, a small RNA reglator of the acid response in Escherichia coli. J. Bacteriol. 186: 6698-6705.

Papenfort, K., and Vogel, J. (2014) Small RNA functions in carbon metabolism and virulence of enteric pathogens. Front. Cell. Infect. Microbiol. 4: 91.

Raina, M., King, A., Bianco, C., and Vanderpool, C.K. (2018) Dual-function RNAs. Microbiol. Spectr. 6: RWR-0032-2018.

Rhoads, D.B., Tai, P.C., and Davis, B.D. (1984) Energy-requiring translocation of the OmpA protein and alkaline phosphatase of Escherichia coli into inner membrane vesicles. J. Bacteriol. 159: $63-70$.

Robinson, J.J., and Weiner, J.H. (1980) The effect of amphipaths on the flavin-linked aerobic glycerol-3-phosphate dehydrogenase from Escherichia coli. Can. J. Biochem. 58: 1172-1178. 
Rowlett, V.W., Mallampalli, V.K.P.S., Karlstaedt, A., Dowhan, W., Taegtmeyer, H., Margolin, W., and Vitrac, H. (2017) Impact of membrane phospholipid alterations in Escherichia coli on cellular function and bacterial stress adaptation. J. Bacteriol. 199: pii: e00849-00816.

Schryvers, A., Lohmeier, E., and Weiner, J.H. (1978) Chemical and functional properties of the native and reconstituted forms of the membrane-bound, aerobic glycerol-3-phosphate dehydrogenase of Escherichia coli. J. Biol. Chem. 253: 783-788.

Soberón-Chávez, G., Alcaraz, L.D., Morales, E., Ponce-Soto, G.Y., and Servín-González, L. (2017) The transcriptional regulators of the CRP family regulate different essential bacterial functions and can be inherited vertically and horizontally. Front. Microbiol. 8: 959.

Storz, G., Wolf, Y.I., and Ramamurthi, K.S. (2014) Small proteins can no longer be ignored. Annu. Rev. Biochem. 83: 753-777.

Updegrove, T.B., Zhang, A., and Storz, G. (2016) Hfq: the flexible RNA matchmaker. Curr. Opin. Microbiol. 30: 133-138.

Urban, J.H., and Vogel, J. (2009) A green fluorescent protein (GFP)-based plasmid system to study post-transcriptional control of gene expression in vivo. Methods Mol. Biol. 540: 301-319.

Vanderpool, C.K., and Gottesman, S. (2004) Involvement of a novel transcriptional activator and small RNA in post-transcriptional regulation of the glucose phosphoenolpyruvate phosphotransferase system. Mol. Microbiol. 54: 1076-1089.

Venkat, K., Hoyos, M., Haycocks, J.R.J., Cassidy, L., Engelmann, B., Rolle-Kampczyk, U., Tholey, A., Grainger, D.C., and Papenfort, K. (2021) A dual-function RNA balancing carbon uptake and central metabolism in Vibrio cholerae. Submitted.

Wadler, C.S., and Vanderpool, C.K. (2007) A dual function for a bacterial small RNA: SgrS performs base pairing-dependent regulation and encodes a functional polypeptide. Proc. Natl. Acad. Sci. USA 104: 20454-20459.

Wagner, E.G.H., and Romby, P. (2015) Small RNAs in bacteria and archaea: who they are, what they do, and how they do it. Adv. Genet. 90: 133-208.

Walz, A.C., Demel, R.A., de Kruijff, B., and Mutzel, R. (2002) Aerobic sn-glycerol-3-phosphate dehydrogenase from Escherichia coli binds to the cytoplasmic membrane through an amphipathic alpha-helix. Biochem. J. 365: 471-479.

Wang, H., Yin, X., Wu Orr, M., Dambach, M., Curtis, R., and Storz, G. (2017) Increasing intracellular magnesium levels with the 31-amino acid MgtS protein. Proc. Natl. Acad. Sci. USA 114: 5689-5694.

Wang, X., Ji, S.C., Yun, S.H., Jeon, H.J., Kim, S.W., and Lim, H.M. (2014) Expression of each cistron in the gal operon can be regulated by transcription termination and generation of a galKspecific mRNA, mK2. J. Bacteriol. 196: 2598-2606. 
Weaver, J., Mohammad, F., Buskirk, A.R., and Storz, G. (2019) Identifying small proteins by ribosome profiling with stalled initiation complexes. mBio 10: pii: e02819-02818.

Wegener, M., Vogtmann, K., Huber, M., Laass, S., and Soppa, J. (2016) The glpD gene is a novel reporter gene for $E$. coli that is superior to established reporter genes like lacZ and gusA. J. Microbiol. Methods 131: 181-187.

Yeh, J.I., Chinte, U., and Du, S. (2008) Structure of glycerol-3-phosphate dehydrogenase, an essential monotopic membrane enzyme involved in respiration and metabolism. Proc. Natl. Acad. Sci. USA 105: 3280-3285.

Yu, D., Ellis, H.M., Lee, E.C., Jenkins, N.A., Copeland, N.G., and Court, D.L. (2000) An efficient recombination system for chromosome engineering in Escherichia coli. Proc. Natl. Acad. Sci. USA 97: 5978-5983.

Zeghouf, M., Li, J., Butland, G., Borkowska, A., Canadien, V., Richards, D., Beattie, B., Emili, A., and Greenblatt, J.F. (2004) Sequential Peptide Affinity (SPA) system for the identification of mammalian and bacterial protein complexes. J. Proteome Res. 3: 463-468.

Zhang, A., Wassarman, K.M., Ortega, J., Steven, A.C., and Storz, G. (2002) The Sm-like Hfq protein increases OxyS RNA interaction with target mRNAs. Mol. Cell 9: 11-22. 


\section{Figure Legends}

\section{Figure 1. AzuC protein synthesis is regulated at a post-transcriptional level.}

A Diagram of the AzuCR RNA and sequence of the $a z u C$ promoter and coding region. Boxes and text in light blue denote AzuC coding sequence and yellow box and highlighted text denote region of base pairing with target mRNAs. The AzuCR transcript is indicated in bold with the +1 site of transcription (position 1988001 of the E. coli K-12 genome) in green font and the $3^{\prime}$ end of the transcript in red font. The ribosome binding site and the start and stop codons of the AzuC ORF are indicated by black boxes. Potential $\sigma^{70}-10$ and -35 sequences are underlined, the predicted CRP binding sites are highlighted in light gray (Hemm et al., 2010), and the region targeted by the FnrS sRNA is highlight in dark gray.

B Immunoblot blot analysis of AzuC-SPA levels (top) and northern blot analysis of $a z u C$ mRNA levels (bottom) for cells grown in with different carbon sources. Cultures of the azuC-SPA::kan (GSO351) or unmarked (MG1655) strains were grown in M63 medium supplemented with glucose, glycerol, or galactose at $\mathrm{pH} 7.0$ or 5.5. Samples were taken at $\mathrm{OD}_{600} \sim 0.5$ and 1.5. $\alpha$-FLAG antibody was used to detect the SPA tag. The membrane was stained with Ponceau S stain to control for loading. The $a z u C$ mRNA and 5S RNA were detected by oligonucleotide probes specific to each of these transcripts.

C Immunoblot blot analysis of AzuC-SPA levels in $h f q^{+}(\mathrm{GSO} 351)$ and $\Delta h f q$ (GSO1007) cells grown in with different carbon sources. Strains were grown in the same media as in (B) and collected at $\mathrm{OD}_{600} \sim 1.5$. Immunoblot blot analysis also was carried out as in (B).

\section{Figure 2. AzuC protein is membrane associated.}


A Helical wheel projection generated using NetWheels (Mól et al., 2019) showing amphipathic nature of AzuC. Mutations introduced in $(\mathrm{C})$ are indicated.

B Fractionation of AzuC-SPA strain. A culture expressing AzuC-SPA (GSO351) was grown in M63 glucose medium to $\mathrm{OD}_{600} \sim 0.5$, and cells were fractionated into a soluble, inner membrane, and pellet fractions, which were compared to the whole cell lysate. The top panel shows AzuC-SPA as detected with $\alpha$-FLAG antibody. The bottom panel shows the outer membrane OmpA control detected with $\alpha$-OmpA antibody.

C Microscopy of AzuC-GFP. AzuC-GFP (GSO1008) and AzuC $\mathrm{I}_{\mathrm{I} L \mathrm{~L} 7 \text { to E6E7-GFP mutant }}$ (GSO1009) cells were grown in M63 glucose medium to $\mathrm{OD}_{600} \sim 0.5$ to observe membrane localization by fluorescent microscopy. Left panels are fluorescent images showing GFP labeled AzuC, and the right panels are the corresponding brightfield images. Insets provide an enlargement of a few cells.

\section{Figure 3. AzuC copurifies with GlpD.}

A GlpD co-purifies with AzuC-SPA. Cells expressing AzuC-SPA (GSO351) or AcrZ-SPA (GSO350) from the chromosome were grown in M63 glucose medium to $\mathrm{OD}_{600} \sim 1.0$ or in LB to $\mathrm{OD}_{600} \sim 0.6$, respectively. The cell lysates were split and passed over calmodulin beads. Eluants from each column were subjected to SDS-PAGE followed by Coomassie blue staining. The bands enriched in the eluant from the calmodulin beads and indicated by the arrows were excised from the gel and identified by mass spectrometry.

B AzuC-SPA co-purifies with GlpD-HA-His 6 . Cells expressing either AzuC-SPA (GSO351) or GlpD-HA-His 6 (GSO1011) from the chromosome were grown in M63 glucose or M63 glycerol media, respectively, to $\mathrm{OD}_{600} \sim 1.0$ and mixed in a 1:1 ratio. As a control, cells 
expressing MgtA-HA (GSO785) grown in $\mathrm{N}$ medium supplemented without added $\mathrm{MgSO}_{4}$ to $\mathrm{OD}_{600} \sim 0.5$, were mixed with the AzuC-SPA (GSO351) cells in the same ratio. The mixed cells were homogenized, cell lysates (L) were applied to $\alpha$-HA beads and the flow-through (FT) samples were collected. The beads were washed (W), after which the bound proteins were eluted (E) and examined on immunoblots using either $\alpha$-HA antibodies to detect MgtAHA or GlpD-HA-His 6 (top panel) or $\alpha-F L A G$ antibodies to detect AzuC (bottom panel).

\section{Figure 4. AzuC increases GlpD activity and affects cell shape.}

A Effect of AzuC overexpression on GlpD activity. WT or $\triangle a z u C: \because k a n$ cells (top panel), $\Delta a z u C:: k a n$ (GSO193) (middle panel) or $\Delta a z u C \Delta g l p D:: k a n$ (GSO1015) (bottom panel) cells transformed with $\mathrm{pKK}, \mathrm{pKK}-\mathrm{AzuC}$, and $\mathrm{pKK}-\mathrm{AzuC} \mathrm{L}_{\mathrm{LSTOp}}$ were grown in $\mathrm{M} 63$ glucose medium to $\mathrm{OD}_{600} \sim 1.0$. Cells were washed and resuspended in M63 glycerol medium, pH 5.5 for $3 \mathrm{~h}$ prior to incubation with MTT and measurement of $\mathrm{A}_{570}$ reflecting the reduction of MTT to formazan, which is coupled to the oxidation of glycerol-3-phosphate to DHAP.

B Effect of AzuC overexpression on E. coli cell morphology. $\triangle a z u C: \because k a n$ (GSO193) transformed with $\mathrm{pKK}$, pKK-AzuC, $\mathrm{pKK}-\mathrm{AzuC} \mathrm{L}_{\mathrm{L} \text { STOP, }}$ or $\mathrm{pKK}-\mathrm{GlpD}$ were grown in $\mathrm{M} 63$ glucose medium to $\mathrm{OD}_{600} \sim 1.0$. Cells were washed and resuspended in M63 glycerol medium, $\mathrm{pH} 5.5$ for $3 \mathrm{~h}$ prior to microscopy.

\section{Figure 5. FnrS sRNA represses synthesis of both AzuC and GlpD.}

A Predicted base pairing between FnrS and $a z u C$. The coordinates for both are relative to the +1 of the transcript. 
B Effect of FnrS overexpression on AzuC-SPA levels. Cultures of the azuC-SPA::kan (GSO351) strain carrying pBR, pBR-FnrS, pBR-FnrS-I, pBR-FnrS-II, or pBR-FnrS-III were grown in LB with $1 \mathrm{mM}$ IPTG to $\mathrm{OD}_{600} \sim 0.5$. $\alpha$-FLAG antibodies were used to detect the SPA tag.

C Predicted base pairing between FnrS and $g l p D$. The predicted region of pairing in $g l p D$ is within the coding sequence. The coordinates for FnrS are relative to the +1 of the transcript, while the coordinates for $g l p D$ are relative to the first nucleotide of the start codon.

D Effect of FnrS overexpression on GlpD-HA-His6 levels. Cultures of the glpD-HA-His6 (GSO1011) strain carrying pBR, pBR-FnrS, pBR-FnrS-I, pBR-FnrS-II, or pBR-FnrS-III were grown in LB with $1 \mathrm{mM}$ IPTG to $\mathrm{OD}_{600} \sim 0.5$. $\alpha$-His antibodies were used to detect GlpD-HA-His6.

For (B) and (D), the membrane was stained with Ponceau S stain to control for loading.

Figure 6. AzuC and AzuR overexpression leads to different growth phenotypes in different carbon sources.

Growth of the $\triangle a z u C:: k a n$ strain (GSO193) transformed with pKK, pKK-AzuC, pKK-

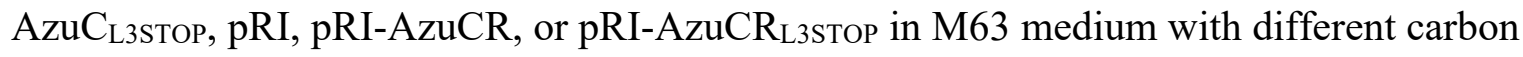
sources, glucose ( $\mathrm{pH} 7.0)$, glycerol ( $\mathrm{pH} 7.0$ and 5.5), and galactose ( $\mathrm{pH} 7.0)$, was measured $16 \mathrm{~h}$ after dilution by $\mathrm{OD}_{600}$. The full growth curves are in Fig EV5A.

\section{Figure 7. AzuR represses $c a d A$ and galE expression.}

A AzuCR-cadA base pairing predicted by TargetRNA2 (Kery et al., 2014). The coordinates for AzuCR are relative to the +1 of the transcript, while the coordinates for $c a d A$ are relative to 
the first nucleotide of the start codon. Mutations introduced into AzuCR and cadA are indicated.

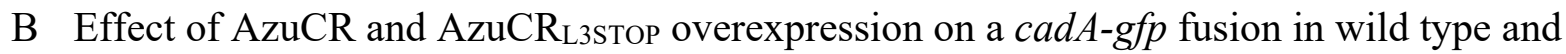
$\triangle a z u C$ backgrounds. WT and $\Delta a z u C:: k a n$ (GSO193) cells were co-transformed with a reporter plasmid expressing a cadA-gfp translational fusion and either the empty pRI vector, AzuCR, or AzuCRL3stop.

C Test of AzuCR-cadA base pairing. $\triangle a z u C:: k a n$ (GSO193) cells were cotransformed with the WT cadA-gfp translational fusion reporter plasmid or a M1 derivative with mutations in the predicted region of base pairing along with the empty $\mathrm{pRI}$ vector, $\mathrm{AzuCR}_{\mathrm{L} 3 \mathrm{STOP}}$, or mutant $\mathrm{AzuCR}_{\mathrm{L3STOP}-\mathrm{M} 1}$. The mutations in the $\operatorname{cadA-gfp}$ translational fusion and $\mathrm{AzuCR}_{\mathrm{L} 3 \mathrm{STOP}}$ are indicated (A).

D AzuCR-galE base pairing predicted by IntaRNA (Mann et al., 2017). The coordinates for AzuCR are relative to the +1 of the transcript, while the coordinates for galE are relative to the first nucleotide of the start codon. Mutations introduced into AzuCR and galE are indicated.

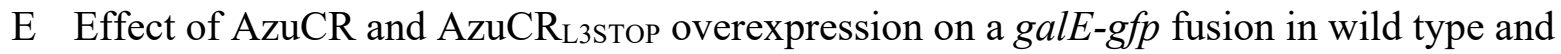
$\triangle a z u C$ backgrounds. WT and $\triangle a z u C:: k a n$ (GSO193) cells were co-transformed with a reporter plasmid expressing a galE-gfp translational fusion and either the empty pRI vector, AzuCR or AzuCR 23 STop.

F Test of AzuCR-galE base pairing. $\triangle a z u C:: k a n$ (GSO193) cells were cotransformed with the WT galE-gfp translational fusion reporter plasmid or a M2 derivative with mutations in the predicted region of base pairing along with the empty $\mathrm{pRI}$ vector, $\mathrm{AzuCR}_{\mathrm{L} 3 \mathrm{STOP}}$, or mutant 
AzuCR $_{\text {L3STOP-M2. The mutations in the galE-gfp translational fusion and AzuCR }}$ L3STOP are indicated in (D).

For (B), (C), (E) and (F), cells were grown in LB for $3 \mathrm{~h}$ before measuring the fluorescence corresponding to GFP expression. The average of three independent trials is shown, and the error bars represent one SD.

Figure 8. AzuCR mRNA and base pairing activities are differentially affected by Hfq and ProQ.

A AzuCR co-immunoprecipitation with Hfq and ProQ. Extracts from MG1655 (GSO982), $\Delta h f q-c a t:: s a c B$ (GSO954) and $\Delta p r o Q:: k a n$ (GSO956) cells grown in M63 glucose were incubated with $\alpha-\mathrm{Hfq}$ or $\alpha-P r o Q$ antiserum. Total and RNA chaperone-bound RNA was extracted and subjected to Northern analysis using an oligonucleotide probe specific for AzuCR.

B Effect of $\Delta h f q:: k a n$ (GSO955), $\Delta$ proQ::kan (GSO956) and $\Delta h f q \Delta p r o Q:: k a n$ (GSO959) double mutant on AzuCR repression of cadA-gfp. cadA-gfp expression from pXG10-SF in the presence of $\mathrm{AzuCR}$ or $\mathrm{AzuCR}_{\mathrm{L} 3 \mathrm{STOP}}$ in WT, $\Delta h f q$ or $\Delta p r o Q$ backgrounds. The average of three independent trials is shown, and the error bars represent one SD.

C Effect of $c a d A_{\text {base pairing, }} c a d A_{\text {control, }}$ galE $E_{\text {base pairing }}$ and galE $E_{\text {control }}$ on AzuC-SPA levels in cells (GSO351) transformed with the respective overexpression plasmid and grown in M63 medium supplemented with glucose or galactose. Samples were taken at $\mathrm{OD}_{600} \sim 0.5$ and $\alpha-$ FLAG antibody was used to detect the SPA tag. The membranes stained with Ponceau S stain serves as a loading control. 
D Model for the different functions of the AzuCR RNA. For growth in M63 glycerol, pH 5.5, the RNA can be translated to give the 28 amino acid amphipathic AzuC protein, which increases the activity of GlpD glycerol-3-phosphate dehydrogenase. Under anaerobic conditions this translation and the translation of GlpD is blocked by the FnrS sRNA. The RNA can also act as the AzuR base-pairing sRNA to repress synthesis of CadA and GalE. 


\section{Expanded View Figures}

\section{Figure EV1. Ribosome binding to and conservation of $a z u C$.}

A The $a z u C$ open reading frame lies within a region that was previously reported to encode the IsrB sRNA (Chen et al., 2002). Translation is detected by ribosome density on the isrB gene for an untreated control (gray) (Weaver et al., 2019), and cells treated with the translation inhibitors Onc112-treated (blue) (Weaver et al., 2019) or retapamulin-treated (red) (Meydan et al., 2019).

B The AzuC amino acid sequences from E. coli K12 and other bacterial species aligned with ClustalW (Madeira et al., 2019). “*” indicates the residues are identical in all sequences and “:” and "." respectively indicate that conserved and semi-conserved substitutions as defined by ClustalW.

Figure EV2. Fractionation showing subcellular localization of untagged AzuC and AzuCSPA co-purification with GlpD-HA-His 6 compared to untagged control strain.

A AzuC was overexpressed at low levels from the arabinose-inducible $\mathrm{P}_{\mathrm{BAD}}$ promoter on the multicopy pAZ3 plasmid derivative of pBAD18 (Kawano et al., 2005). After induction with arabinose, cell extracts were fractionated into periplasmic, cytoplasmic, and membrane fractions. The fractions were then examined on immunoblots using polyclonal $\alpha$-AzuC primary antibody followed by $\alpha$-rabbit secondary antibody. AzuC expressed from the chromosome could not be detected by the polyclonal $\alpha$-AzuC antibody.

B AzuC-SPA cells grown in M63 glucose and MG1655 cells or GlpD-HA-His6 cells grown in M63 glycerol, to $\mathrm{OD}_{600} \sim 1.0$ were mixed in a 1:1 ratio. The mixed cells were homogenized, 
cell lysates (L) were applied to anti-HA beads and the flow-through (FT) fractions were collected. The beads were washed (W), after which the bound proteins were eluted (E) and examined on immunoblots using either $\alpha$-HA antibodies to detect GlpD-HA-His 6 (top panel) or $\alpha-F L A G$ antibodies to detect AzuC (bottom panel).

Figure EV3. Effect of AzuC overexpression on GIpD levels at pH 5.5 and on GIpD activity at pH 7.0.

A $\Delta a z u C$ cells expressing GlpD-HA-His 6 (GSO1013) were transformed with pKK, pKK-AzuC, and $\mathrm{pKK}-\mathrm{AzuC}_{\mathrm{L} 3 \mathrm{STOP}}$, grown in $\mathrm{M} 63$ glycerol medium to $\mathrm{OD}_{600} \sim 0.5$ and examined on immunoblots using $\alpha-\mathrm{HA}$ antibodies to detect GlpD-HA-His 6 . The membrane was stained with Ponceau S stain to control for loading.

B MG1655 or $\Delta a z u C$ (GSO193) cells (top panel) or $\Delta a z u C$ (GSO193) cells transformed with

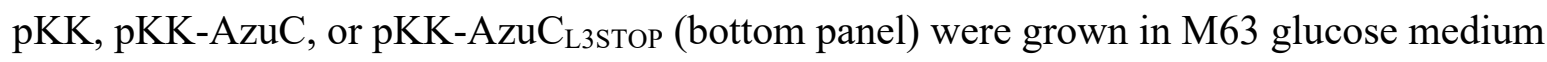
to $\mathrm{OD}_{600} \sim 0.5$ and then washed and resuspended in M63 glycerol medium at $\mathrm{pH}$ 7.0. Cells were allowed to grow for an additional $3 \mathrm{~h}$ at which point the dehydrogenase activity assay was performed.

\section{Figure EV4. FnrS sRNA represses AzuC expression.}

A AzuC-SPA levels in strains lacking Hfq or FnrS. AzuC-SPA levels in WT (GSO351), $\Delta h f q$ (GSO1007) or $\Delta f n r S$ (GSO1023) strains grown in LB to $\mathrm{OD}_{600} \sim 0.5$. $\alpha$-FLAG antibody was used to detect the SPA tag.

B $\beta$-galactosidase activity was assayed for $\mathrm{P}_{\mathrm{BAD}}-5^{\prime}-\mathrm{UTR}_{a z u C^{-}} l a c Z$ (GSO1024) or $\mathrm{P}_{\mathrm{BAD}}-5^{\prime}-$ UTR $_{a z u c-l a c Z}$-III (GSO1025) cells carrying pBR, pBR-FnrS or pBR-FnrS mutants (pBR- 
FnrS I, II or III). Cells were grown to $\mathrm{OD}_{600} \sim 0.4-0.5$ and treated with either just arabinose $(0.2 \%)$ (black bars) or arabinose $(0.2 \%)$ and IPTG $(1 \mathrm{mM})$ (white bars), and cells were grown another $40 \mathrm{~min}$. The average of three independent trials is shown, and the error bars represent one SD.

\section{Figure EV5. Growth curves for AzuC and AzuCR overexpression.}

A $\Delta a z u C:: k a n$ strain (GSO193) transformed with pRI, pRI-AzuCR, pRI-AzuCR L3STop, $_{\text {pKK, }}$ pKK-AzuC, or pKK-AzuC $\mathrm{L}_{\text {3STop }}$ was grown in M63 medium with different carbon sources: glucose (pH 7.0), glycerol (pH 7.0 and 5.5), and galactose (pH 7.0) and growth was tracked by $\mathrm{OD}_{600}$ over $30 \mathrm{~h}$.

B Growth of the $\triangle a z u C:: k a n$ strain (GSO193) transformed with $\mathrm{pKK}, \mathrm{pKK}-\mathrm{AzuC}, \mathrm{pKK}-$ $\mathrm{AzuC}_{\mathrm{L} 3 \mathrm{ST}}$, or $\mathrm{pKK}$-AzuC-SPA in $\mathrm{M} 63$ medium with glycerol $\mathrm{pH} 5.5$ was measured at $16 \mathrm{~h}$ after dilution by $\mathrm{OD}_{600}$. 
bioRxiv preprint doi: https://doi.org/10.1101/2021.04.27.441574; this version posted April 27, 2021. The copyright holder for this preprint (which

was not certified by peer review) is the author/funder, who has granted bioRxiv a license to display the preprint in perpetuity. It is made available under aCC-BY 4.0 International license.

\section{Supplemental Tables}

Appendix Figure S1. Strains used in study.

Appendix Figure S2. Plasmids used in study.

Appendix Figure S3. Oligonucleotides used in study. 
A

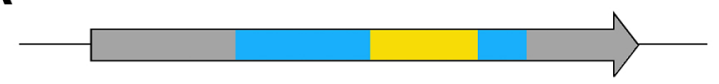

GGGCTGTTTTTTGATTATCATITTTATAACATTAAAGGGGTATITATGTGATTT GTATCACATAAAGATTGATTTTTGTGATGGTTGTCATATTATAAGCGCAAAGAC AATAACACCTGIATAACAAATGGTCGGAGTGCCGCGTGAACTGCGCAAAATC MetIysLeuArgIysile

CTGAAAAGTATGTTCAATAACTATTGCAAGACGITCAAAGACGTACCGCCAGGC LeuIys SerMetPheAsnAsnTyrCysLys ThrPheLysAspValProProGly AATATGTTCCGA TAACAAAAAACCTGCTCCGGCAGGTTTTTTTGTGTCCTGATG AsnMetPheArg
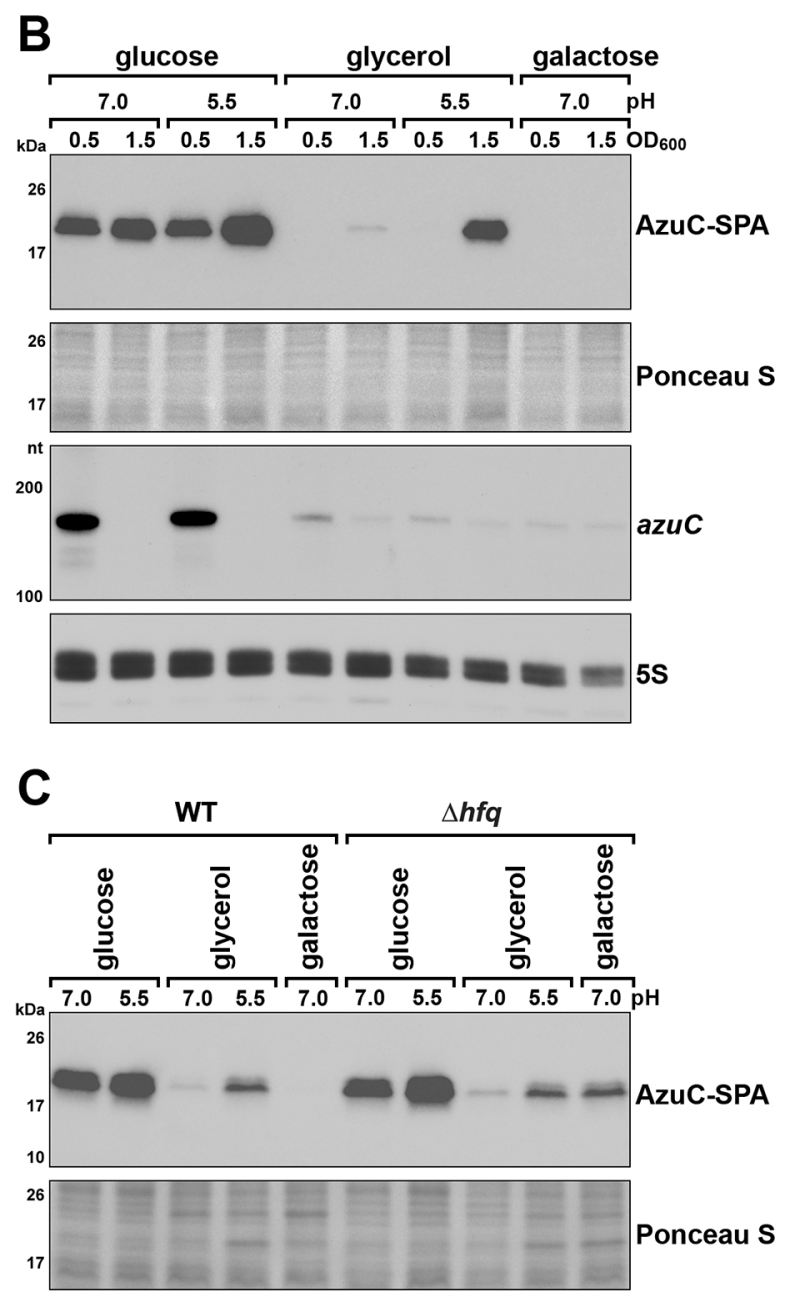
Fig 2
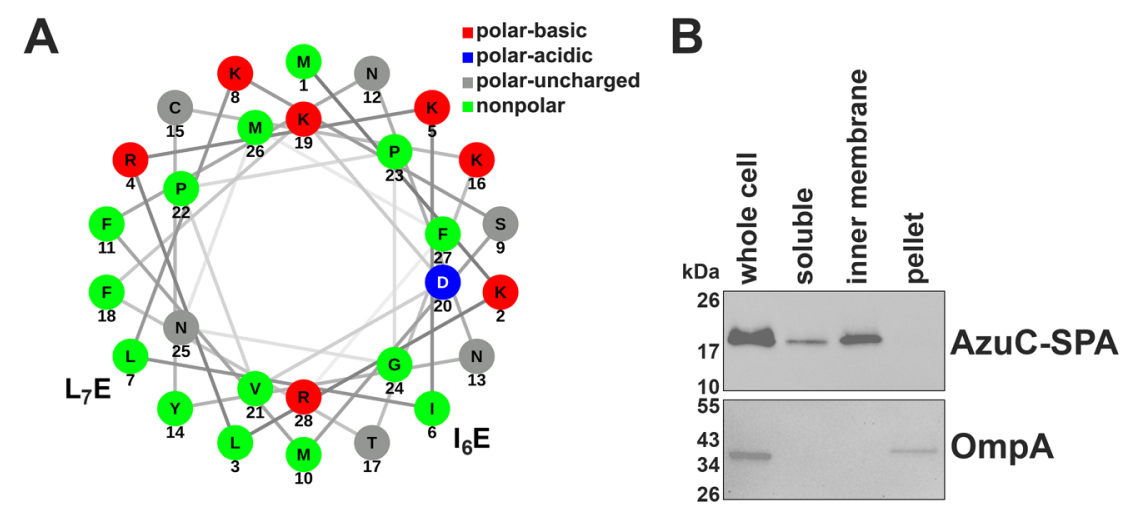

\section{C}
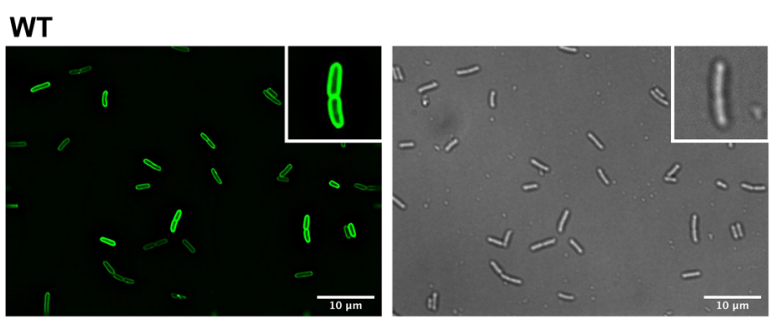

$\mathrm{I}_{6} \mathrm{~L}_{7}$ to $\mathrm{E}_{6} \mathrm{E}_{7}$
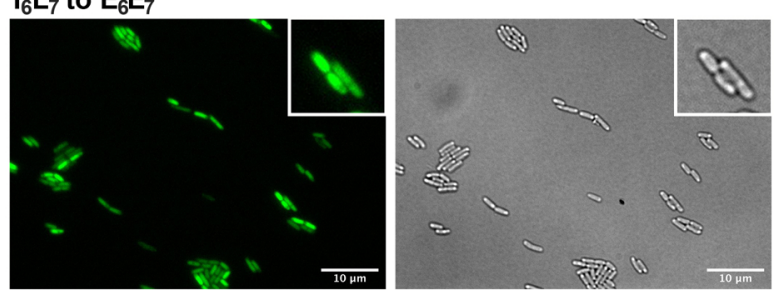
Fig 3
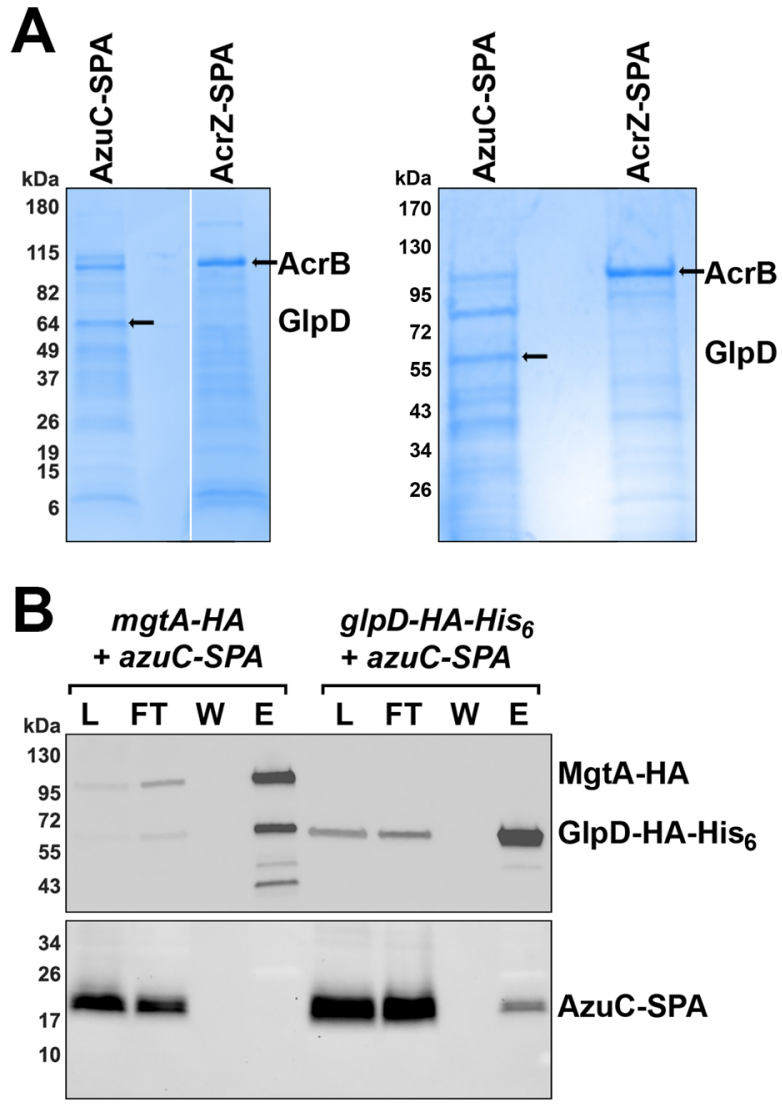
Fig 4

A
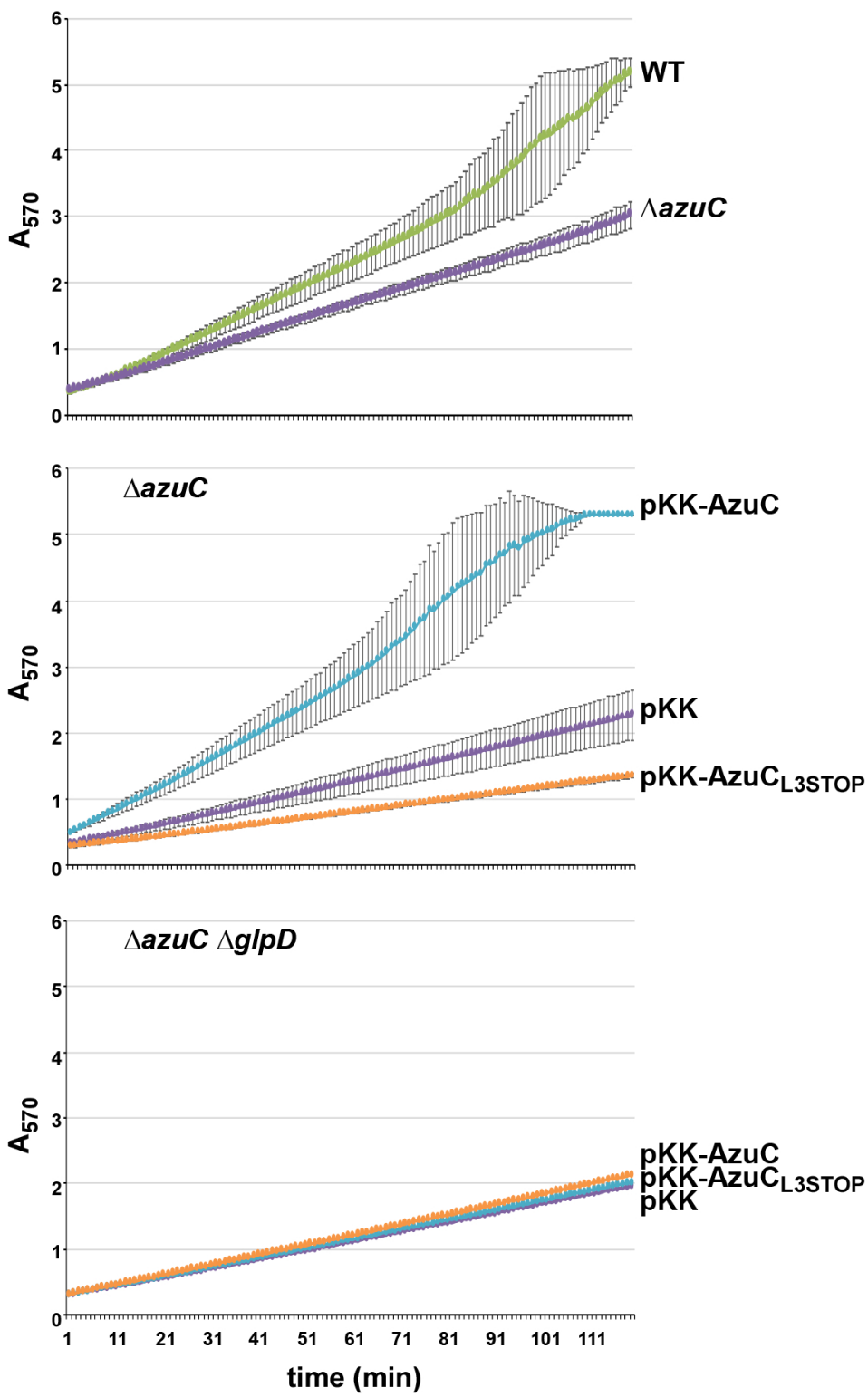

B

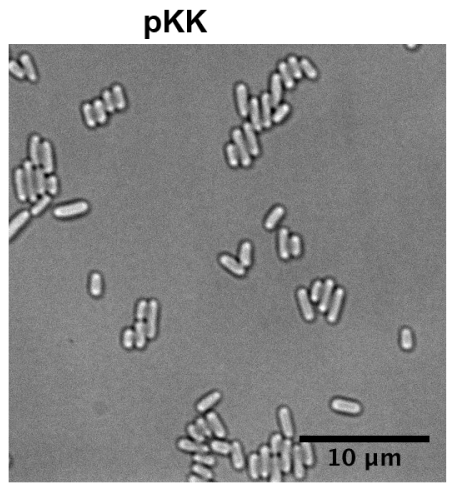

pKK-AzuC

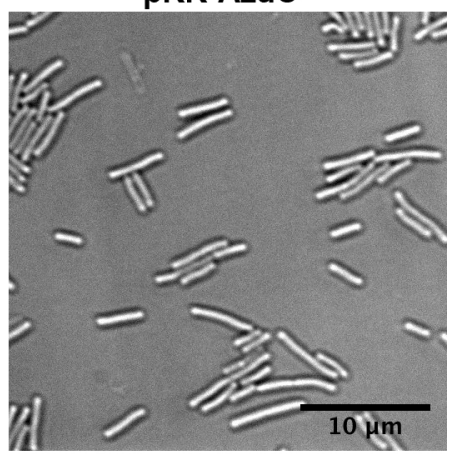

pKK-AZUC ${ }_{L 3 S T O P}$

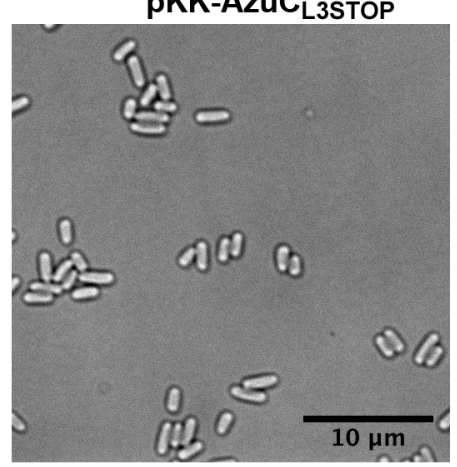

pKK-GIpD

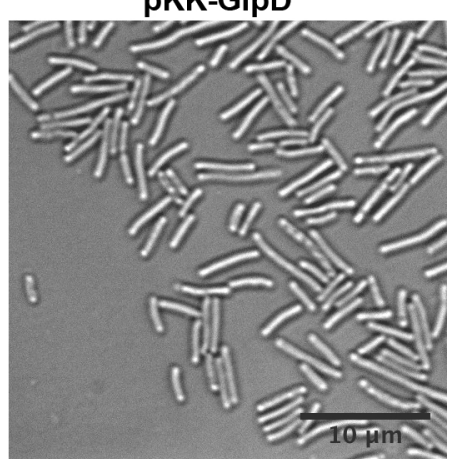


Fig 5

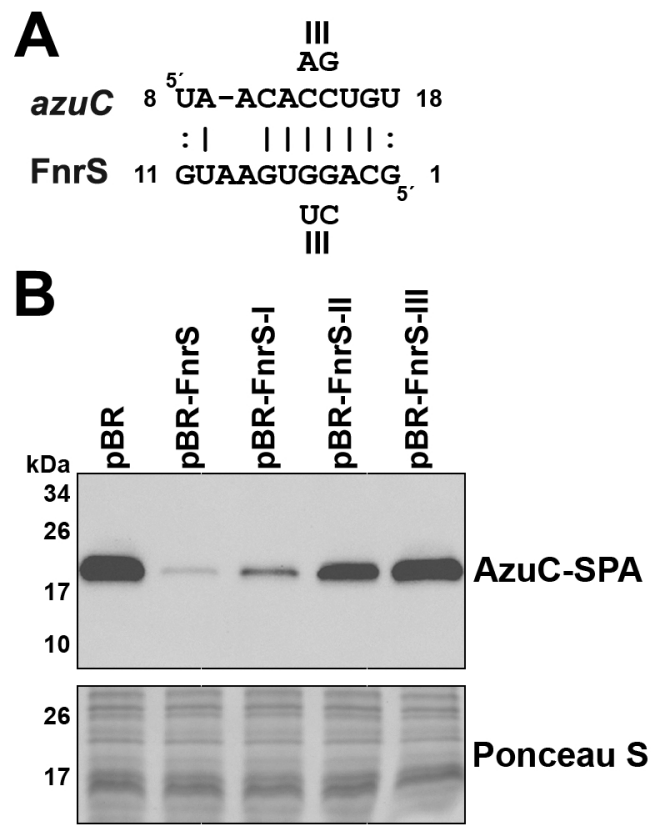

\section{C}

glpD $674{ }^{5}$ GCAUUCGCCUG 684
||||||$:||||$
FnrS 12 CGUAAGUGGAC, 2

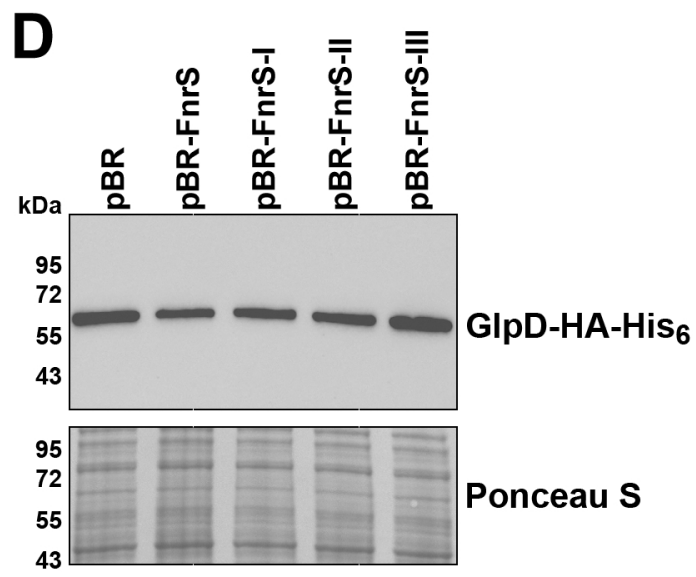


Fig 6
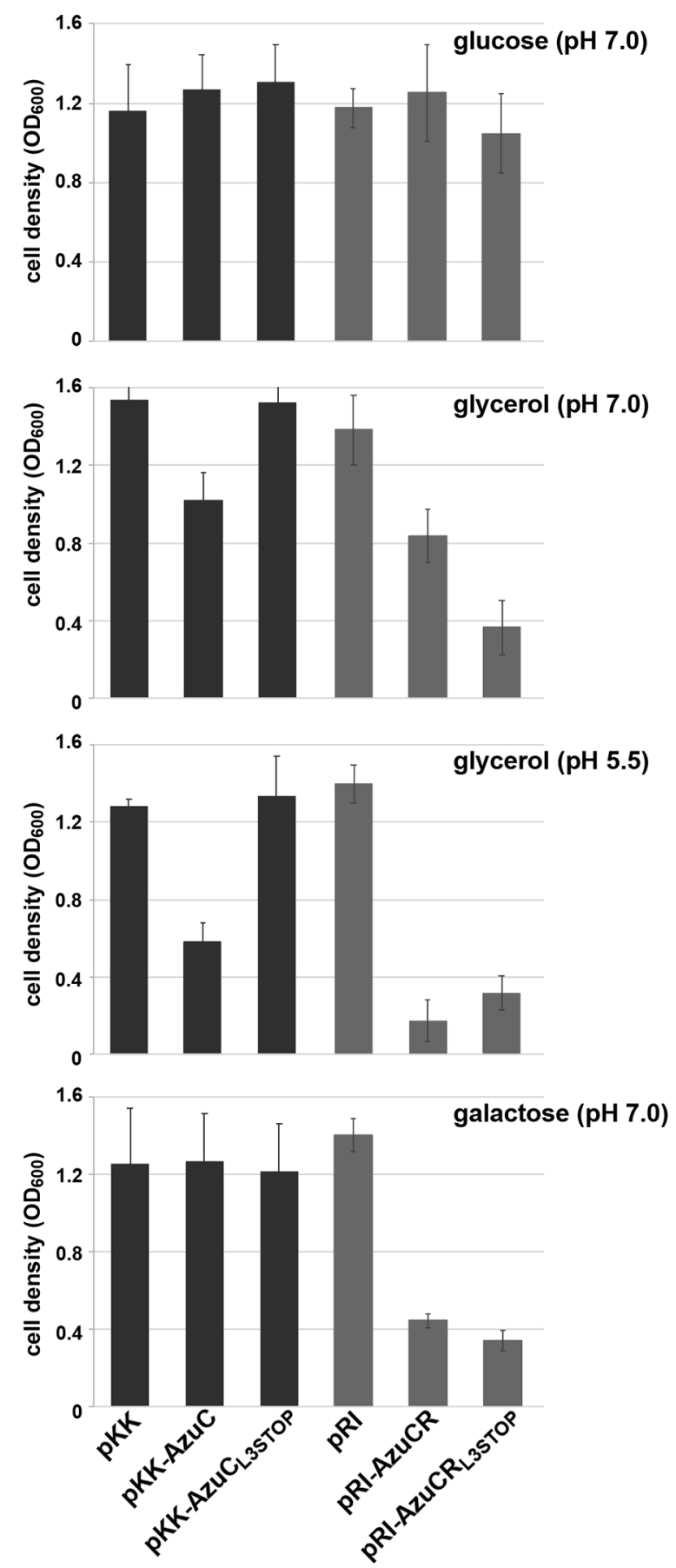
$\begin{array}{lllll}\text { A } & \text { M1 } & \text { D } & \text { M2 }\end{array}$

AzUCR $82^{5}$ UAUUGCAA-GACGUUCAAAGACGUACCGCCAGG 113 AZUCR $81^{5}$ CUAUUGCAA-GACGUUCAAAGAC-GUACCGCCAG 112 IIIIIIII:IIIIIIIIII $1: 11111111$ cadA 18 AUAACGUUAUUGCAAGUAUCAGUAUAGAGGUCC 5 - 15

|:||:|| ||||| ||| || |||||||

galE 742 GGUAGCGGUGCUGCA-----CUGGCA-GGCGGUC, 715 GUU

M1

B

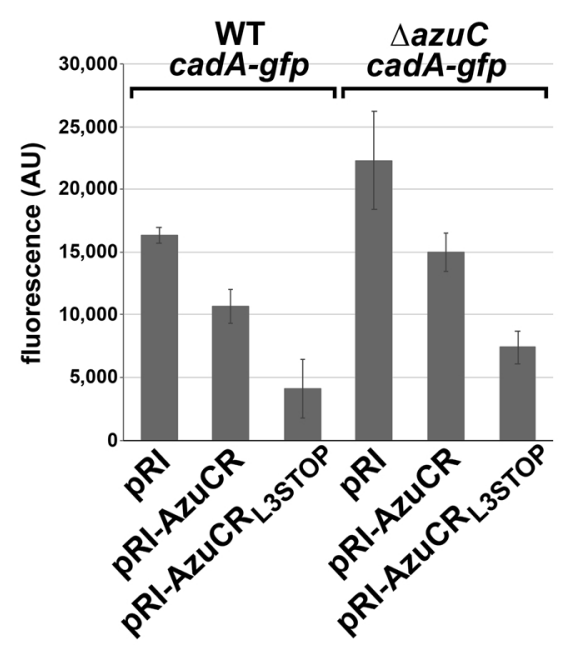

C

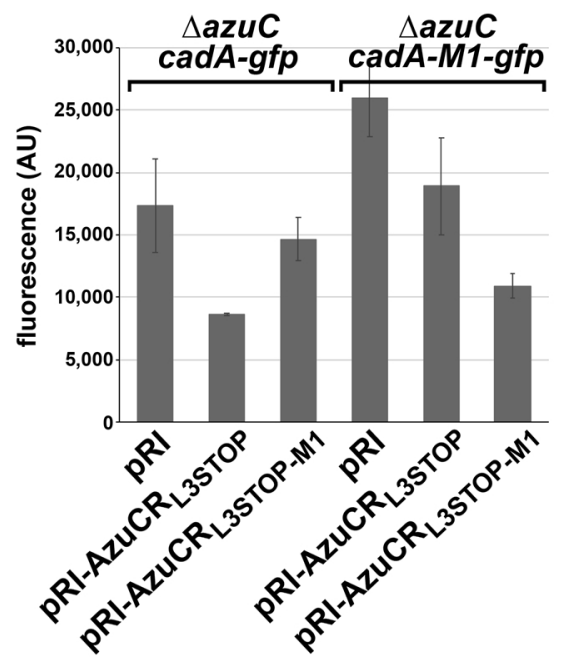

M2

E

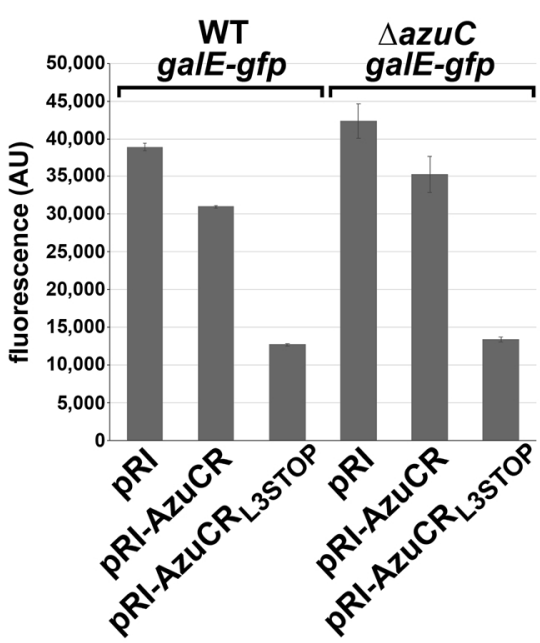

$\mathbf{F}$

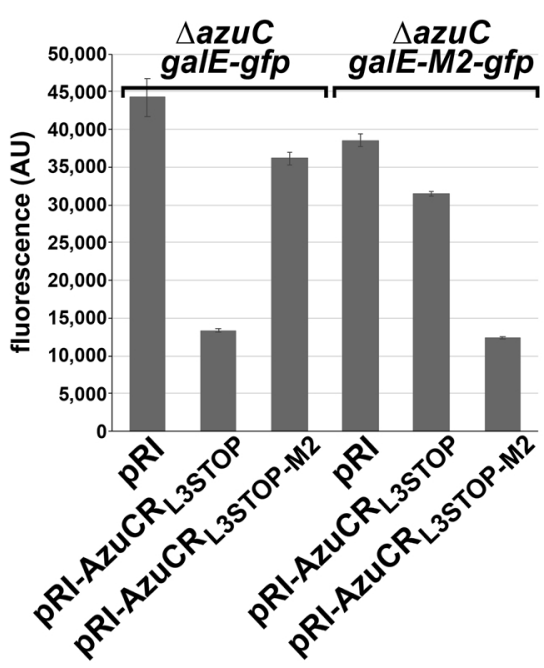


Fig 8

A

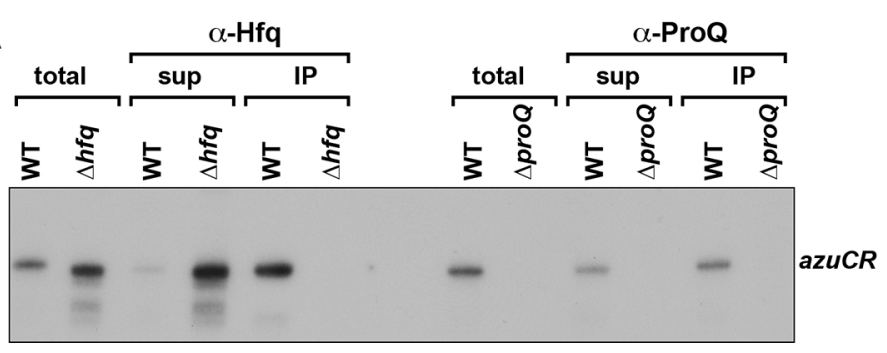

B

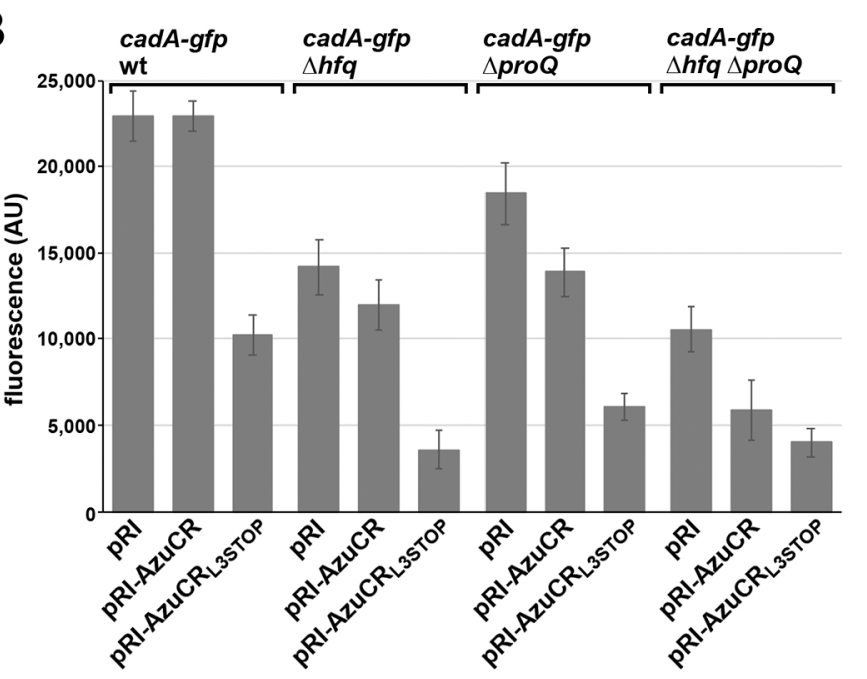

C
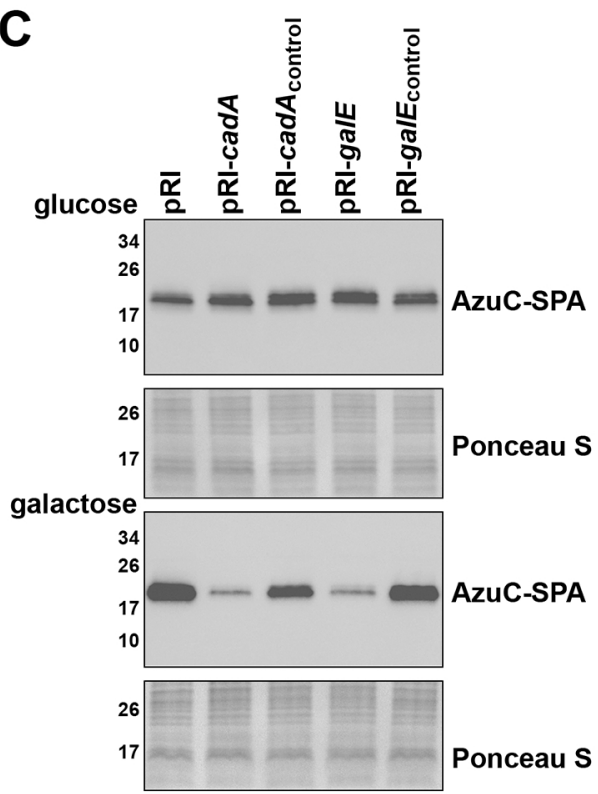

D

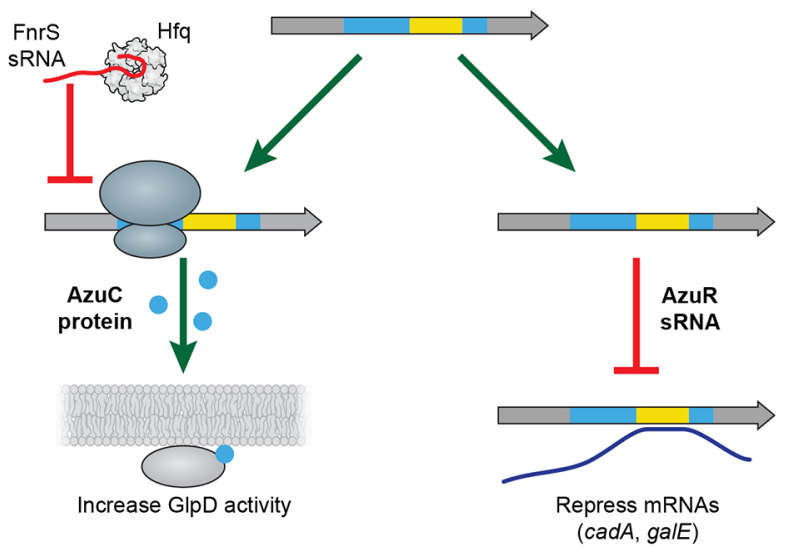


Fig EV1

A

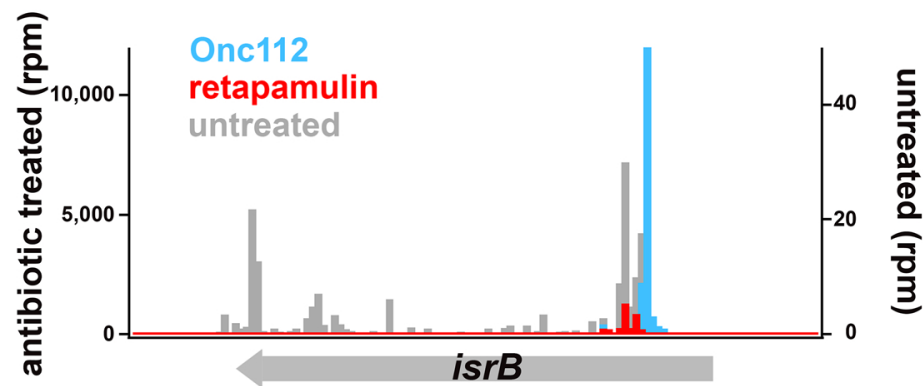

B

Escherichia_coli

Erwinia teleogrylli

Enterobacter_cloacae

Siccibacter turicensis

Raoultella planticola

Cronobacter sakazakii

Buttiauxella warmboldiae

Klebsiella_michiganensis

Kluyvera intermedia

Citrobacter amalonaticus

Mangrovibacter_plantisponsor
--MKLRKILKSMFNNYCKTFKDVPPGNMFR --MKLRNILKSMFESYCNTFKDVPPGALH--MKLRKI LKNMWANYCNT FKDVPP GAMF--MKLRKI LKSMFENYCNTEKDVPPGAMF--MKLRKILKSMFEQYCKTFKDVPPVGMF--MKLRKNLKSMFENYCKTEKDVPPAGMF--MKLRNVLKSMFENYCKTFKDVPPGGMF--MKLRKILKSMFENYCKTFKDVPPGSMFMKQRIRKILKSMFENYCKTFKDVPPGAMF--MTLRKILKSMFENYCKTFKDVPPGAMF--MKLRRILKSMF ENYCKTFKDVPPGAMF- 
Fig EV2
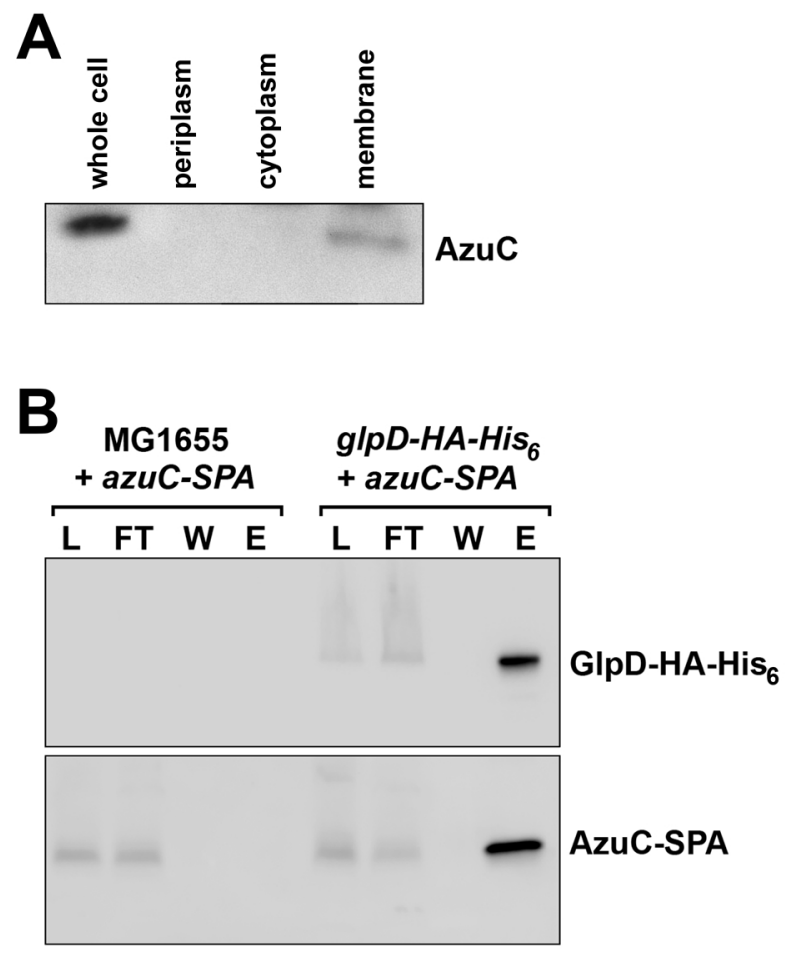
Fig EV3

A

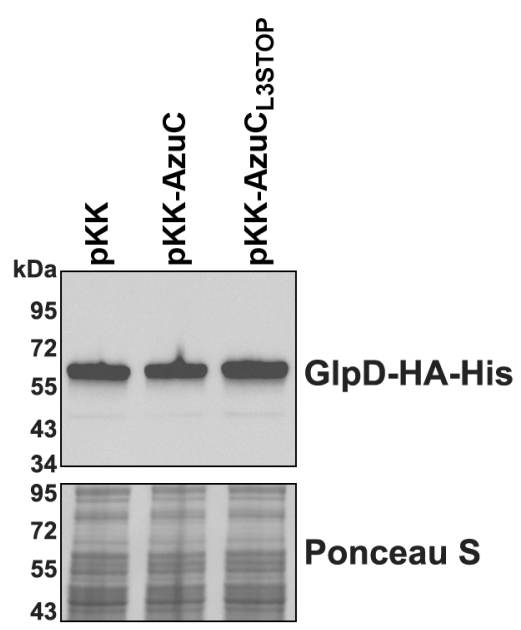

B

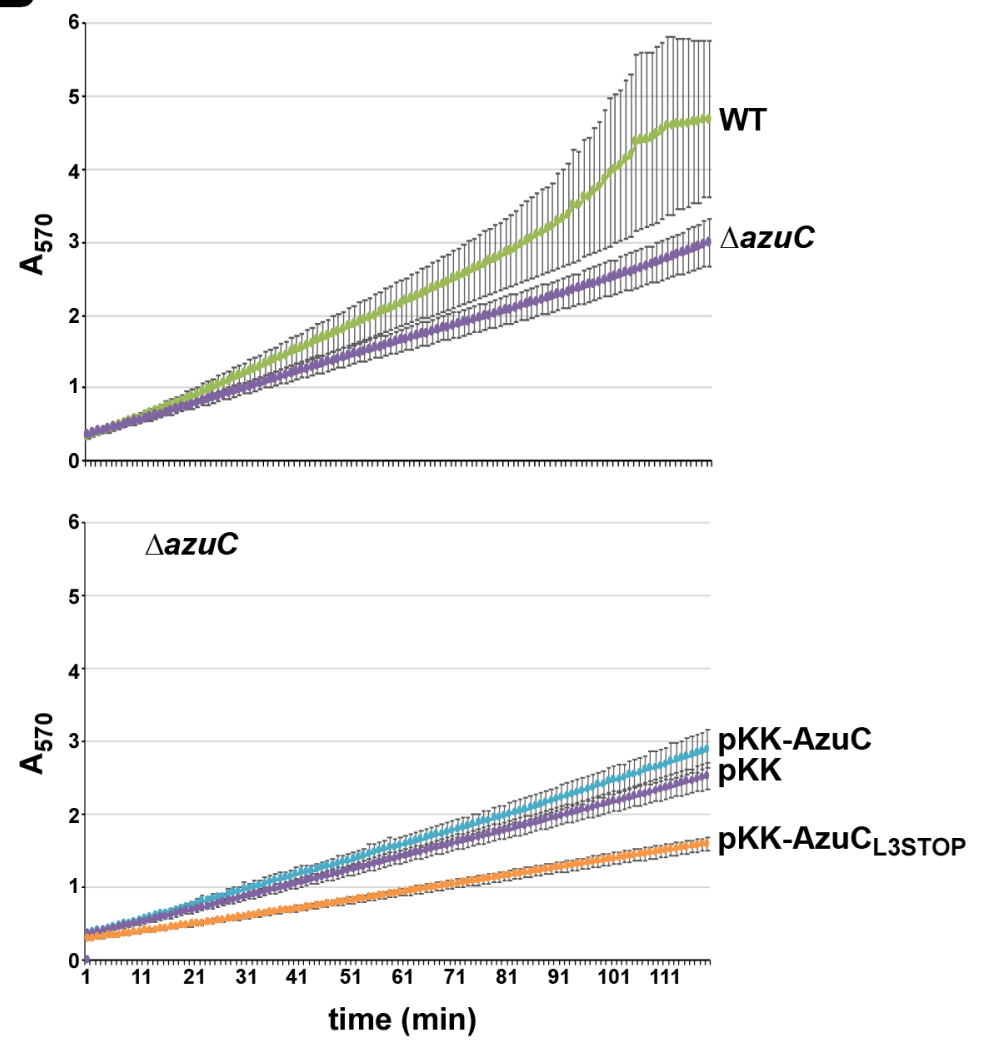



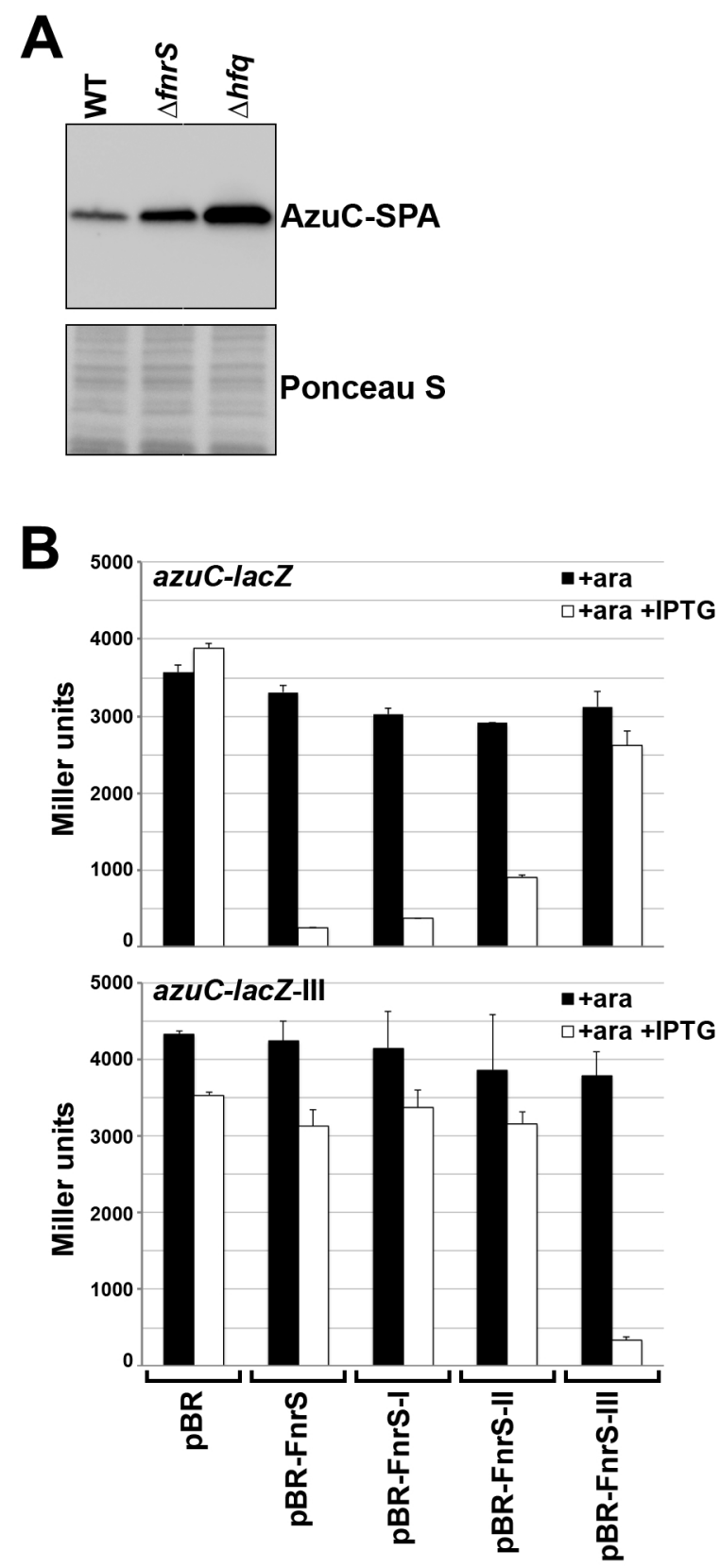


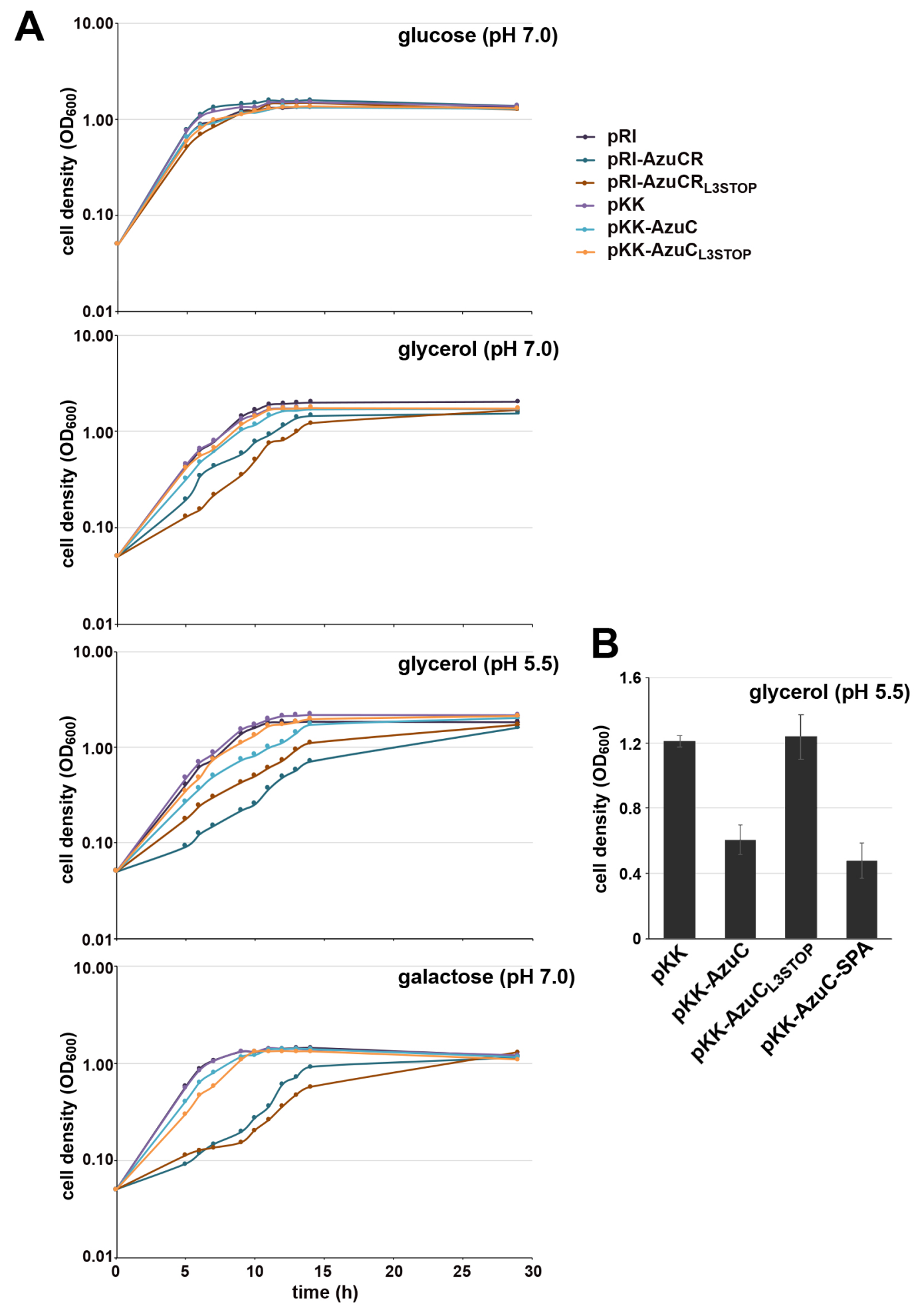

